\title{
Development of Superplastic Structural Ceramics
}

\author{
I-Wei Chen* and Liang An Xue* \\ Department of Materials Science and Engineering, \\ University of Michigan, Ann Arbor, Michigan 48109-2136
}

Superplastic structural ceramics ( $\mathrm{Y}$-TZP, $\mathrm{Al}_{2} \mathrm{O}_{3}, \mathrm{Si}_{3} \mathrm{~N}_{4}$, and their composites) that can withstand biaxial stretching to large strains have been developed recently. Microstructural design of these ceramics first requires an ultrafine grain size that is stable against coarsening during sintering and deformation. A low sintering temperature is a necessary, but not a sufficient, condition for achieving the required microstructure. In many cases, the selection of an appropriate phase, such as tetragonal phase in zirconia or a phase in silicon nitride, which is resistant to grain growth, is crucial. The use of sintering aids and grain-growth inhibitors, particularly those that segregate to the grain boundaries, can be beneficial. Second-phase particles are especially effective in suppressing static and dynamic grain growth. Another major concern is to maintain an adequate grain-boundary cohesive strength, relative to the flow stress, to mitigate cavitation or grain-boundary cracking during large strain deformation. Existing evidence suggests that a lower grainboundary energy is instrumental in achieving this objective. The selection of an appropriate phase and the tailoring of the grain boundary or liquid-phase composition can sometimes drastically alter the cavitation resistance. Related observations on forming methods, forming characteristics, and sheet formability are also reviewed. The basic deformation characteristics are similar to diffusional creep and are dominated by

R. E. Newnham-contributing editor

Manuscript No. 197477. Received June 18, 1990; approved June 26, 1990.

Supported by U.S. Air Force Office of Scientific Research under Grant No. 87-0289, U.S. Department of Energy under Grant No. DE. FG02-87ER45302, and U.S. Army Research Office under Contract No. DAAL03-89-K0133.

* Member, American Ceramic Society. grain-boundary diffusion. However, deformation characteristics are frequently altered by interface reactions, secondphase hardening/softening, and dynamic grain-growth-induced strain hardening. Ductility and formability, on the other hand, are controlled by the flow stress and flaw distribution, not by deformation instability as in superplastic metals. AnaIytical models and empirical correlations are presented to describe various constitutive relations pertaining to superplastic ceramics. [Key words: structural materials, superplastics, models, grain boundaries, microstructure.]

\section{Introduction}

SUPERPLASTICITY is phenomenologically defined as the ability of a material to exhibit exceptionally large tensile elongation during stretching. ${ }^{1,2}$ It is a property commonly found in many metals and alloys when the grain size is refined below several micrometers and the deformation temperature is above two-thirds of the melting point. ${ }^{2}$ At such small sizes micrograins can flow, much like sand particles in a watersaturated slip, by way of atomic diffusion along grain boundaries. Models of diffusional creep and grain-boundary sliding, which predict a nearly Newtonian flow rate inversely proportional to the grain size to a certain power, have been advanced to explain such a phenomenon. 1,3-7 The details of these mechanistic models, however, have received only limited experimental corroboration, and the exact mechanisms of superplasticity are still controversial to this date. Despite such uncertainties, these materials intrinsically embody a high resistance to strain localization, or necking, in tensile deformation because necking necessarily entails a higher local strain rate and thus a higher local flow stress, which will be resisted by the rest of the body.3.8 Several commercial processes in metal industries have taken advantage of these

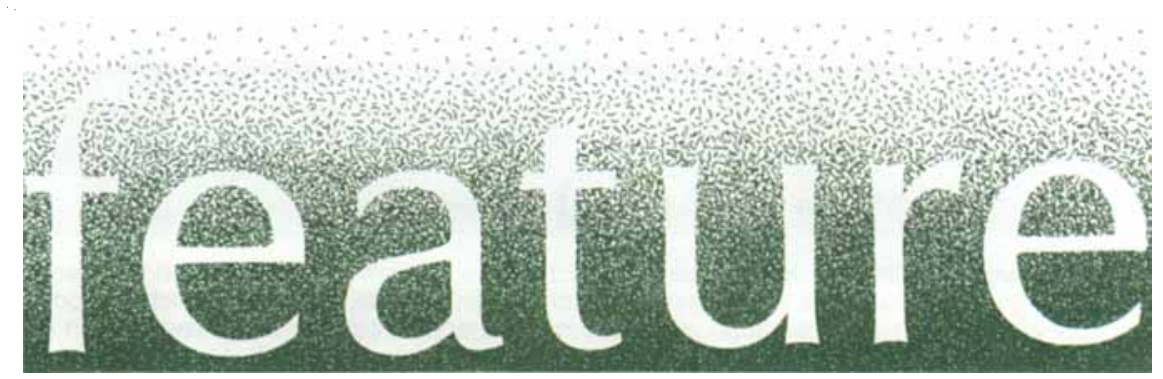


high ductilities to form intricate, large-scale components directly into their net shape. $7,9.10$

Following the report in 1986 of superplasticity in 3Y-TZP,11 a fine-grained tetragonal zirconia partially stabilized by 3 mol\% yttria, considerable research has been conducted to explore the generality of this phenomenon in other ceramics. ${ }^{12}$ Existing evidence indicates that the poiycrystalline ceramics with a grain size below $500 \mathrm{~nm}$ are potentially superplastic at high homologous temperatures. Singlephase ceramics which have been found to be superplastic, i.e., which exhibit large ductility in uniaxial or biaxial stretching, include Y-TZP, ${ }^{11}$ alumina, ${ }^{13}$ and hydroxyapatite. ${ }^{14}$ Polyphase ceramics which have been found to be superplastic include zirconia/alumina, ${ }^{13,15,16}$ zirconia/mullite, ${ }^{17-19}$ silicon nitride, ${ }^{20}$ and silicon nitride/silicon carbide with other mixed phases.21.22 This list is expected to expand in the future.

Several biaxially punch-stretched samples made of various structural ceramics, i.e., zirconia, alumina, silicon nitride, and their composites, are shown in Fig. 1. The broad forming conditions, in terms of forming temperature and forming time, are indicated. The quality of the as-formed sur- faces is excellent. These demonstrations suggest the possibility of deformation processing of dense ceramics at high temperatures (using methods commonly reserved for metals, plastics, and glasses). These processes could include sheet forming, blowing, extrusion, stamping, and forging. Compared with the conventional forming processes of crystalline ceramics, which are conducted at low temperature before firing, these processes have the advantages of greater shape flexibility and better dimensional accuracy. The latter are especially important considerations for netshape forming. ${ }^{9}$

This paper describes various materials considerations which have guided the development of superplastic structural ceramics. The scope of this paper is shown in Fig. 2, which outlines the major factors involved in ceramic superplasticity and their interrelationships. Within this context, we have attempted to critically assess the most significant results in the literature of ceramic superplasticity, and to provide an overview of the highlights of our own effort in this area. The intimate and complicated structure-property-processing relationships in this class of ceramics, which must have an ultrafine microstruc-

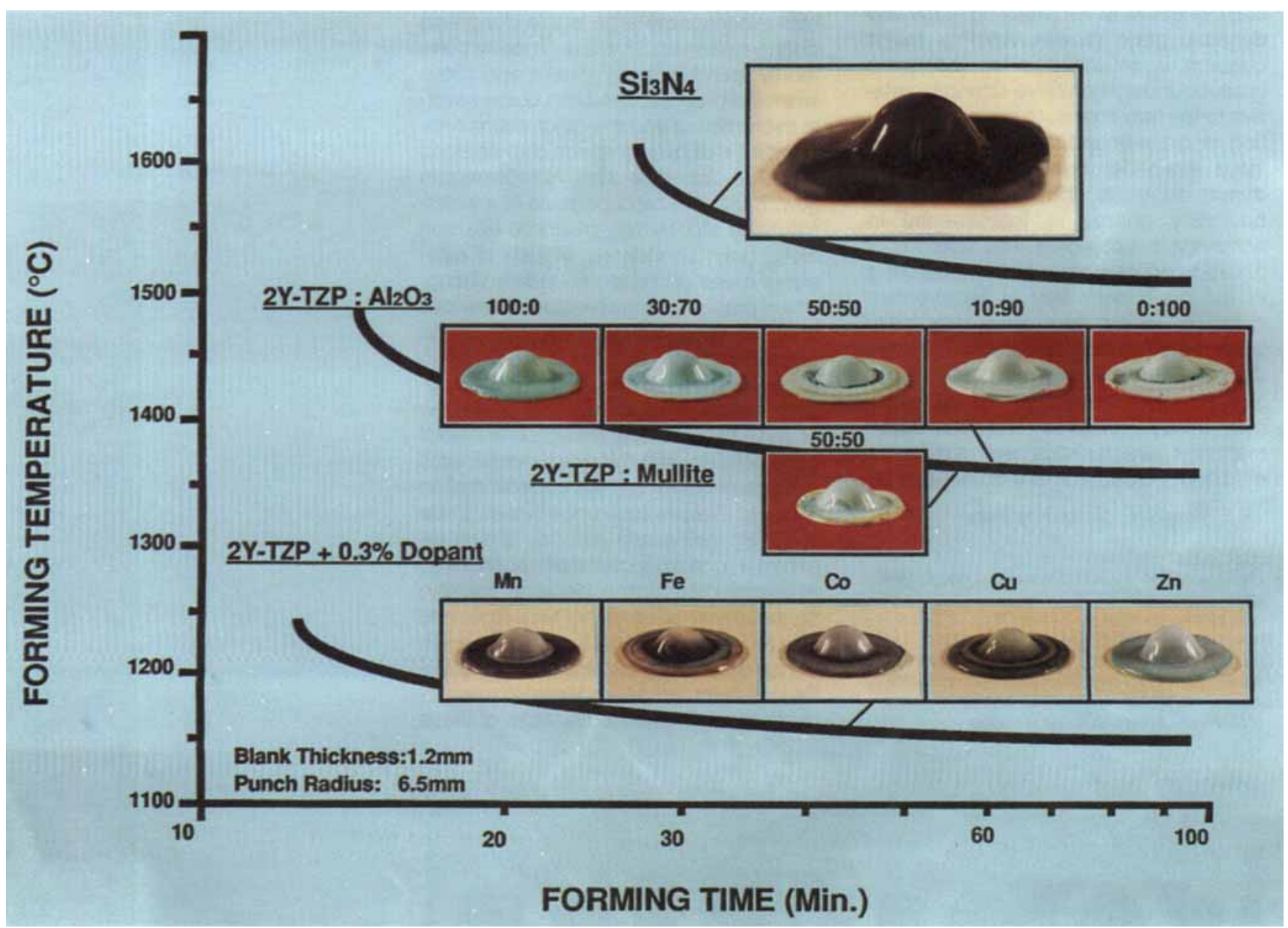

Fig. 1. Superplastic forming temperatures and times of structural ceramics. Hemispherical punch with a 6.5-mm radius was used to stretch the initially flat, 1 -mm-thick disks into the shape shown. Surface finish was excellent and glossy for silicon nitride, zirconia, and zirconia-rich composites. Surface of alumina, although free of visible defects, appeared dull. Under optimal conditions, forming operation can be completed at even lower temperatures and shorter times. 
ture achievable through a judicious crystal structure selection or a second-phase addition, form the subject of Section II of this paper. Deformation characteristics and methods for evaluating formability are described in Sections III and IV to provide further insight into this active research field.

\section{Materials Considerations}

In developing superplastic ceramics, high deformation rate and high ductility are the primary objectives. Practical considerations further dictate that these properties should be achievable at the lowest temperature possible. The basis of materials considerations concerning a high deformation rate and a low deformation temperature lie in the consititutive equation of superplastic flow, which can be expressed in the following form: ${ }^{2}$

$\dot{\varepsilon}=A a^{n} / d^{p}$

where $\dot{\varepsilon}$ is the strain rate, $\sigma$ is the stress, $d$ is the grain size, $n$ and $p$ are stress and grain-size exponents, respectively, and $A$ is a temperature-dependent, diffusionrelated coefficient which can be expressed in an Arrhenius form. For superplastic ceramics, $n$ and $p$ are typically between 1 and 3 . Therefore, a high deformation rate and a low deformation temperature can be achieved by the following steps.

(i) Lowering grain size: Grain-growth control can be achieved through lowtemperature sintering and the use of additives; 23 present practice has found a lower limit of approximately $200 \mathrm{~nm}$ for the grain size in bulk ceramics such as TZP, alumina, silicon nitride, and their composites. Microstructures of some selected superplastic ceramics are shown in Fig. 3.

(ii) Increasing lattice diffusivity, grainboundary diffusivity, or introducing a grainboundary liquid phase as a fast diffusion path: The forming temperature of $\mathrm{Y}-\mathrm{TZP}$ has been lowered from $1350^{\circ}$ to below $1200^{\circ} \mathrm{C}$ with the addition of a small amount of transition-metal oxides which segregate to grain boundaries. ${ }^{24}$ In silicon nitride, a liquid phase is also present which facilitates deformation. 20.21

Although these two steps are necessary, they are not sufficient for achieving superplasticity in a given ceramic for the following reasons. First, in many instances the fine-grained microstructure proves to be unstable under superplastic deformation; i.e., dynamic grain growth may take place. Thus, a fine initial microstructure provides little assurance of the formability of a ceramic. Second, failures of superplastic ceramics appear to be of a brittle intergranular type which is not preceded by extensive necking, unlike most superplastic metals and alloys. Thus, a high cohesive strength at grain boundaries is crucial for achieving high ductility without fracture. Additives for grain refinement or a grain-boundary liquid must be carefully selected so that a high grain-boundary strength is not compromised.

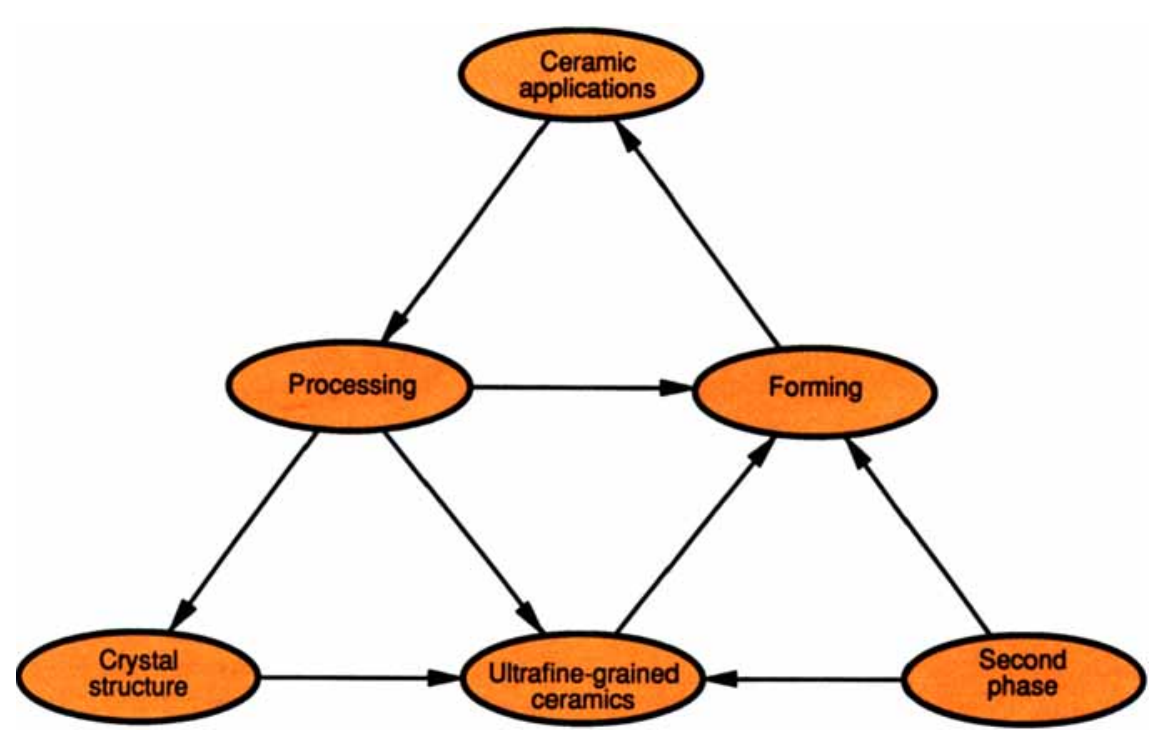

Fig. 2. Structure-property-processing relationships in superplastic ceramics for structural applications.

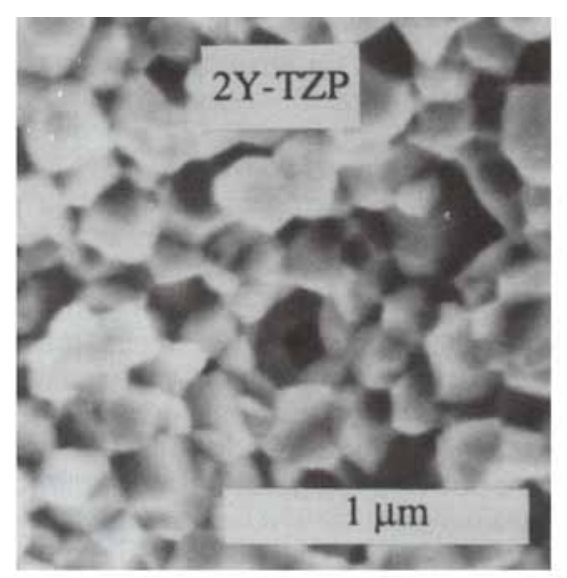

a

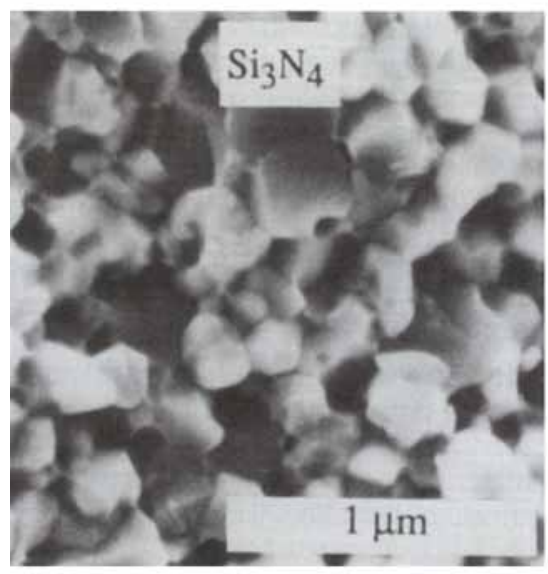

C

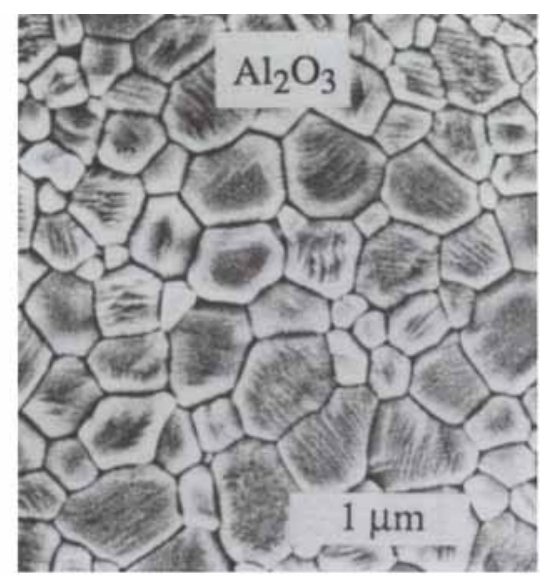

b

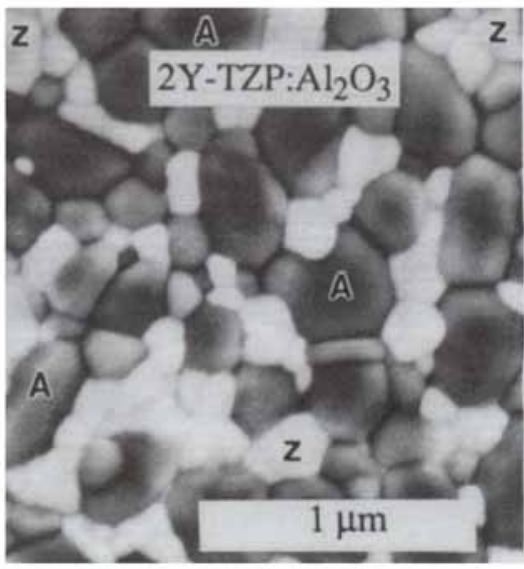

d
Fig. 3. Scanning electron microscopy micrographs of ultrafine grains of superplastic ceramics: (a) 2Y-TZP, (b) alumina, (c) silicon nitride, and (d) 2Y-TZP/alumina at equal volume fraction. 
Prior to the recent discovery of ceramic superplasticity, there was little appreciation or understanding of these aspects in the ceramic field. Therefore, the initial attempts at microstructural and microchemical tailoring of superplastic structural ceramics demanded considerable empiricism. Over the last two years, however, intensive studies on superplastic zirconia and the development of superplastic alumina and silicon nitride collectively provided an extensive body of knowledge on the problems of dynamic grain growth and grain-boundary cohesive strength. They also shed some light on related aspects, such as grain-boundary chemistry, grainboundary mobility, grain-boundary energy, and their relation to deformation and fracture of ultra-fine-grained ceramics.

This knowledge can now be used to formulate some useful and self-consistent guidelines to direct future materials design for superplastic applications. In the following sections, overviews of this knowledge, and the insights derived thereby, are summarized for each class of ceramics to better elucidate the processing-structureforming relationships outlined in Fig. 2.

\section{(1) Zirconia Ceramics}

Tetragonal zirconia polycrystals, containing 2 to $4 \mathrm{~mol} \%$ yttria, have been reported to be superplastic at temperatures above $1300^{\circ} \mathrm{C}, 12$ beginning with the work of Wakai et al. on 3Y-TZP. 11,25-28 For more than a decade, we have known that yttria-stabilized tetragonal zirconia has a characteristically fine-grained microstructure ${ }^{29}$ (see Fig. 3(a)), which is relatively uncommon among ceramics. The need for maintaining a submicrometer grain size was initially motivated by the pursuit of transformation toughening. ${ }^{29-31}$ Ultrafine grains are required to avoid spontaneous tetragonal-to-monoclinic transformation, for which nucleation statistics are grain-size dependent. ${ }^{32}$ The subsequent use of this material as a tough and strong ceramic $\left(K_{I C}\right.$ above 5 $\mathrm{MPa} \cdot \mathrm{m}^{1 / 2}$ and strength exceeding 1200 $\mathrm{MPa})^{33}$ has stimulated the industry to pro vide powders of an excellent sinterability. These commercially available powders can be readily processed to obtain dense ceramics with a grain size ranging from 0.3 to $0.5 \mu \mathrm{m}$, sufficiently fine to allow superplasticity above $1350^{\circ} \mathrm{C}$. It is for this reason that $3 Y-T Z P$ has become almost the universal choice for demonstrating ceramic superplasticity in the last few years.

The relatively good characteristics of zirconia powders contribute to their excellent sinterability and microstructure. The question then becomes, "Is there an intrinsic explanation, if any exists, for the very fine grain size observed?' 34 A related question is whether there is an intrinsic cause for the emergence of $Y$-TZP as an excellent superplastic ceramic. We believe that the answers to both questions have now been given. The primary attributes of Y-TZP as a fine-grained superplas- tic ceramic are closely related to the strong segregation of solute cations to the grain boundary, which lowers the grainboundary mobility and the grainboundary energy. ${ }^{35} \mathrm{~A}$ secondary advantage of TZP appears to be its ability to contain a glassy grain-boundary phase, which facilitates sintering and deformation without compromising microstructural stability and grain-boundary strength.

Direct evidence for $\mathrm{Y}^{3^{+}}$segregation at TZP grain boundaries has been provided by $X$-ray photoelectron spectroscopy (XPS) of intergranularly fractured specimens. ${ }^{36}$ Similar segregation and graingrowth studies on the effects of other cations have revealed a general trend: divalent and trivalent cations are enriched at the grain boundary, whereas tetravalent and pentavalent ones are not. Only the former can suppress grain growth The effectiveness of the dopants $\mathrm{Ca}^{2+}$ $\mathrm{Mg}^{2^{+}}, \mathrm{Y}^{3^{+}}, \mathrm{Yb}^{3^{+}}, \mathrm{In}^{3^{+}}, \mathrm{Sc}^{3^{+}}, \mathrm{Ce}^{4^{+}}, \mathrm{Ti}^{4+}, \mathrm{Ta}^{5^{+}}$ and $\mathrm{Nb}^{5+}$ in suppressing grain growth ranks in the order listed from most to least effective. This sequence can be rationalized if it is recognized that the grain boundary in TZP is positively charged 36 and that larger cations diffuse more slowly. ${ }^{37}$ A schematic diagram illustrating the trend for grain-boundary mobility is shown in Fig. 4. Essentially, from the charge consideration, cations of a valence lower than $4+$ are expected to form a space charge cloud ${ }^{38}$ around the grain boundary, more so for $\mathrm{Ca}^{2+}$ and $\mathrm{Mg}^{2+}$ than for $\mathrm{Y}^{3+}$ and other trivalent cations. Tetravalent and pentavalent cations are not expected to segregate for the same reason. From the size-diffusivity consideration, the solute drag of the larger cation is expected to be more effec. tive, i.e., $\mathrm{Ca}^{2+}$ more than $\mathrm{Mg}^{2+}$, and $\mathrm{Y}^{3^{+}}$ more than $\mathrm{Yb}^{3+}, \ln ^{3^{+}}$, and $\mathrm{Sc}^{3^{+}}$, in that order. Yttrium cations, being trivalent and oversized, with a relatively large (2.5 mol\%) solubility in zirconia, thus serve as a rather effective solute in suppressing grain growth during sintering. It is for this reason that fine-grained Y-TZP is readily obtainable under nearly all processing conditions.

A comparison of the grain-boundary mobility of 2Y-TZP, 12Ce-TZP, 12Ce-TZP with 0.3 and $1 \mathrm{~mol} \%$ calcia, and $8 Y$.CSZ is made in Fig. 5. Compared with Y-TZP, both Ce-TZP and CSZ have a much faster rate of grain growth. Microanalysis of the near grain-boundary region reveals little solute segregation in Ce-TZP and $8 Y$. CSZ. In the case of Ce-TZP, the mobility of the grain boundary can be lowered progressively by adding calcia, which segregates strongly. 36 Calcium, as noted, is the most potent dopant for suppressing grain growth in TZP. Therefore, the observed effects are in accordance with the space charge model.

Rapid grain growth has been observed in a number of materials that have been superplastically deformed. ${ }^{12,39-43}$ Accord- 


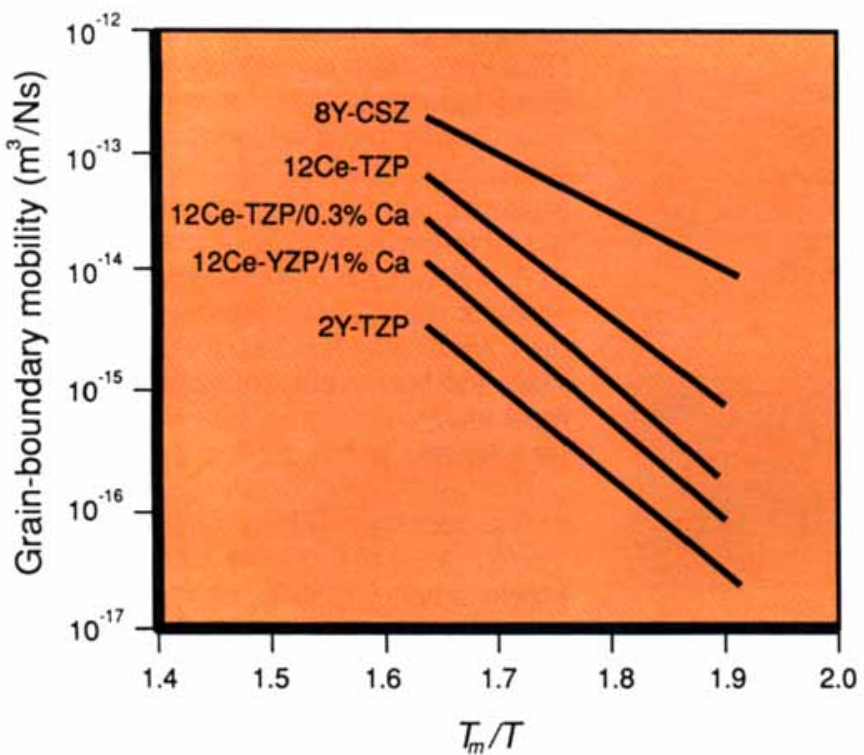

Fig. 5. Grain-boundary mobility of TZP and CSZ plotted versus reciprocal homologous temperature ( $T_{m}$ is melting point).

ing to Eq. (1), grain coarsening during deformation causes an increase of the flow stress. The resultant strain hardening is very pronounced, and it unmistakably signals the occurrence of dynamic grain growth. To illustrate this, stressstrain curves of 2Y-TZP, 12Ce-TZP, $12 \mathrm{Ce}-\mathrm{TZP}$ with 0.3 and $1 \mathrm{~mol} \%$ calcia, and $8 Y$-CSZ are shown in Fig. 6. Among them, $12 \mathrm{Ce}$-TZP and $8 Y$-CSZ exhibit pronounced strain hardening and grain growth, but 2Y-TZP and Ce-TZP with 1 mol\% calcia do not. (These tests were performed in compression to minimize the effect of cavitation or grain-boundary cracking, which is quite severe in $8 Y$. CSZ.) Comparing these results with Fig. 5 , we further note that, even though the addition of $0.3 \mathrm{~mol} \%$ calcia is enough to largely suppress static grain growth, it is inadequate for suppressing dynamic grain growth. It seems likely that, under superplastic deformation, grain boundaries are able to break away from the solute cloud 44 when only $0.3 \mathrm{~mol} \%$ calcia is present. Thus, although solute segregation may still slow down dynamic grain growth, in general, it does so less effectively than that for static grain growth.

In addition to being susceptible to $d y$ namic grain growth, $12 \mathrm{Ce}$-TZP and especially $8 Y$-CSZ seem to cavitate easily, even when deformed in compression. This observation suggests that they have a lower grain-boundary strength than that of $Y$-TZP. A higher grain-boundary energy in $8 Y-C S Z$ than that of $Y$-TZP has been reported based on dihedral angle measurements in the two-phase tetragonal/cubic zirconia ceramics ${ }^{35}$ (see Table I and Fig. 7). Because the dihedral angle is determined by the ratio of the interfacial energies, these data allow the calculation of the relative energies of the tetragonal grain strengths.

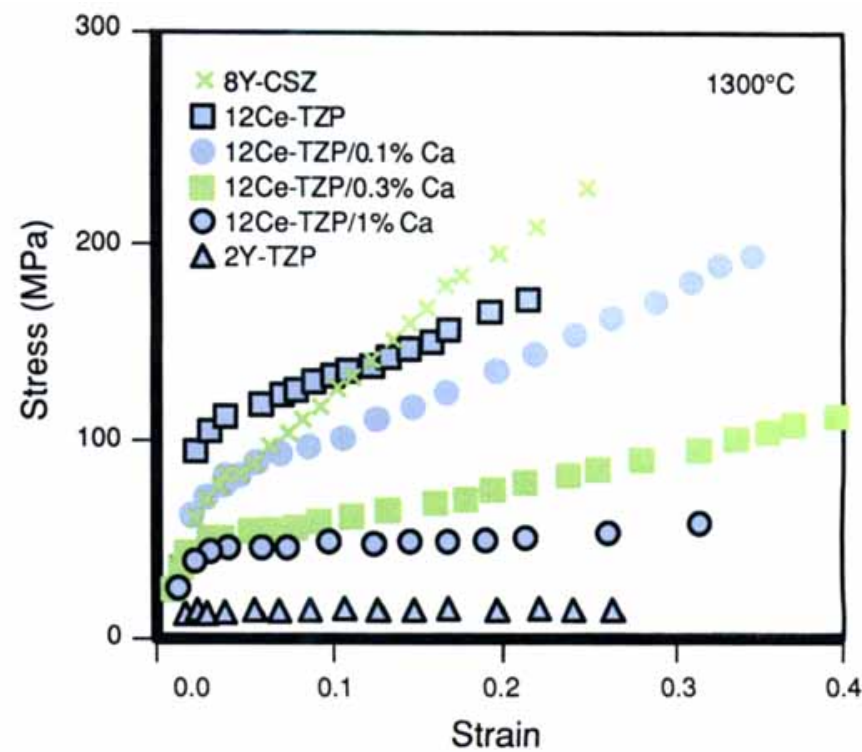

Fig. 6. Stress-strain curves of TZP and CSZ. Initial grain sizes are $0.48 \mu \mathrm{m}(8 Y$-CSZ) $0.56 \mu \mathrm{m}(12 \mathrm{Ce}$-TZP with $0 \%, 0.1 \%$, and $0.3 \% \mathrm{Ca}$ ), $0.3 \mu \mathrm{m}(12 \mathrm{Ce}$-TZP with $1 \% \mathrm{Ca})$, and $0.21 \mu \mathrm{m}$ (2Y-TZP). Tendency for strain hardening directly corresponds to the magnitude of grainboundary mobility shown in Fig. 5. (Strain rate is $10^{-4} \mathrm{~s}^{-1}$ except in the case of $8 \mathrm{Y}$-CSZ and $12 \mathrm{Ce}$-TZP with $1 \% \mathrm{Ca}$ where $3 \times 10^{-4} \mathrm{~s}^{-1}$ is used.)

Table I. Dihedral Angles and Interfacial Energies of Zirconia and Alumina

\begin{tabular}{|c|c|c|c|c|c|}
\hline \multirow[b]{2}{*}{ Ceramic } & \multirow[b]{2}{*}{ Stabilizer } & \multicolumn{2}{|c|}{ Dihedral angle, $\theta$ (deg) } & \multicolumn{2}{|c|}{ Interfacial energy, $y$} \\
\hline & & $\theta_{c, t t}$ & $\theta_{t, c c}$ & $\gamma_{c c} / \gamma_{t t}$ & $\gamma_{t c} \gamma_{c c}$ \\
\hline \multirow[t]{6}{*}{ TZP/CSZ } & $4 \mathrm{~mol} \% \mathrm{Y}_{2} \mathrm{O}_{3}$ & 134 & 97 & 1.7 & 1.3 \\
\hline & $6 \mathrm{~mol} \% \mathrm{Y}_{2} \mathrm{O}_{3}$ & 131 & 105 & 1.5 & 1.2 \\
\hline & $6 \mathrm{~mol} \% \mathrm{Y}_{2} \mathrm{O}_{3}{ }^{*}$ & 134 & 107 & 1.5 & 1.3 \\
\hline & $5.5 \mathrm{~mol} \% \mathrm{In}_{2} \mathrm{O}_{3}$ & 136 & 95 & 1.8 & 1.3 \\
\hline & $5 \mathrm{~mol} \% \mathrm{Sc}_{2} \mathrm{O}_{3}$ & 140 & 113 & 1.6 & 1.5 \\
\hline & & $\theta_{a, t}$ & $\theta_{t, a a}$ & $\gamma_{a a} / \gamma_{t t}$ & $y_{a t} / \gamma_{t t}$ \\
\hline \multirow[t]{2}{*}{ Alumina/zirconia } & Alumina/2Y-TZP & 130 & 90 & 1.67 & 1.18 \\
\hline & & $\theta_{a, c c}$ & $\theta_{c, a a}$ & $\gamma_{a a} / \gamma_{c c}$ & $\gamma_{a d} / \gamma_{a c}$ \\
\hline Alumina/zirconia & Alumina/8Y-CSZ & 114 & 96 & 1.23 & 1.34 \\
\hline
\end{tabular}

boundary $\left(\gamma_{t t}\right)$, cubic grain boundary $\left(\gamma_{C C}\right)$, and tetragonal/cubic phase boundary $\left(\gamma_{t c}\right)$. This gives $\gamma_{t t} \cdot \gamma_{t c} \cdot \gamma_{C C}=1: 1.3: 1.6$ (Similar correlations have also been observed in alumina and its phase boundaries with zirconia, as will be discussed in the next section.) This correlation suggests that an added benefit of solute segrega tion in Y-TZP is the lowering of the grainboundary energy, which could, in turn, have the effect of increasing the cohesive strength of the grain boundary. If this correlation extends to other zirconia ceramics, it also follows that, because they lack solute segregation, both $8 Y$-CSZ and $12 \mathrm{Ce}$-TZP have higher grain-boundary energies and thus lower cohesive

To enhance the diffusivity and lower the deformation resistance of zirconia ceramics, additives which segregate to the grain boundary and which possibly form a grain-boundary low-melting phase can be quite effective. Transition-metal oxides 


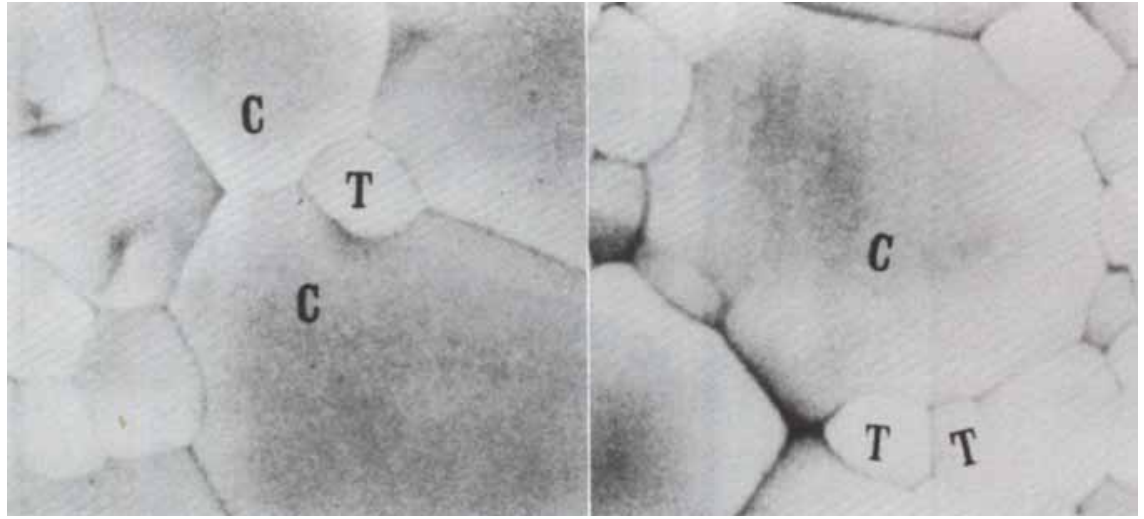

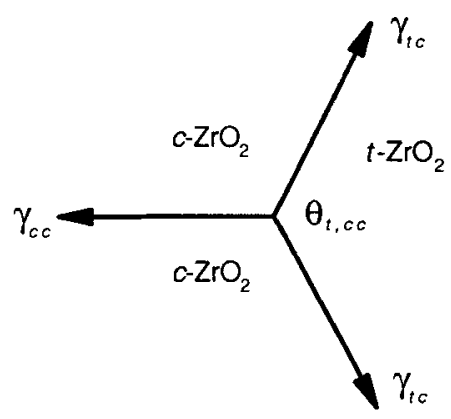

(a)

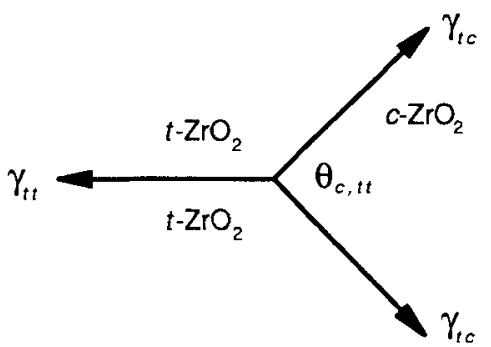

(b)
Fig. 7. Relationship between dihedral angles and interfacial energies: (a) tetragonal grain $(T)$ surrounded by cubic grains (C) in $6 \mathrm{~mol} \%$ yttria/zirconia, indicating $\gamma_{C C}>\gamma_{i c}$ and (b) cubic grain (C) surrounded by tetragonal grains (T) in $4 \mathrm{~mol} \%$ yttria/zirconia, indicating $\gamma_{t t}<y_{t c}$.

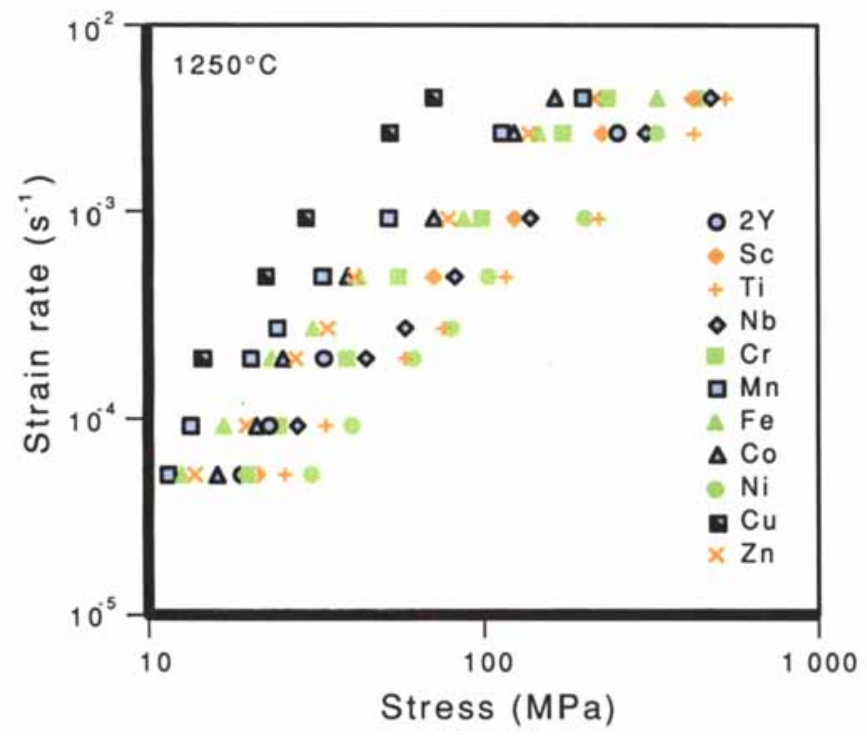

Fig. 8. Strain rate versus stress of TZP with $0.3 \mathrm{~mol} \%$ of cation additive as shown. Base composition contains 2 mol\% yttria and is denoted by $2 Y$.
(Sc, Ti, $\mathrm{Nb}, \mathrm{Cr}, \mathrm{Mn}, \mathrm{Fe}, \mathrm{Co}, \mathrm{Ni}, \mathrm{Cu}$, and $\mathrm{Zn})$ at $0.3 \mathrm{~mol} \%$ have been investigated for this purpose. ${ }^{45}$ Of the above, $\mathrm{Mn}, \mathrm{Co}$, $\mathrm{Ni}$, and $\mathrm{Zn}$ were found to lower the sintering temperature and lower the grain size; Cu was found to lower the sintering temperature but slightly increase the grain size; and $\mathrm{Sc}, \mathrm{Ti}, \mathrm{Nb}$. and $\mathrm{Cr}$ did not aid sintering. Deformation data for $2 Y$ TZP with various dopants, sintered and tested at $1250^{\circ} \mathrm{C}$, are shown in Fig. 8. Figure 8 shows that $\mathrm{Mn}, \mathrm{Fe}, \mathrm{Co}, \mathrm{Cu}$, and $\mathrm{Zn}$ lower the flow stress, with $\mathrm{Cu}$ being the most effective. Segregation of these latter elements to the grain boundary was confirmed by XPS. Additional studies of the Cu-doped 2Y-TZP further established the formation of a grain-boundary liquid phase around $1130^{\circ} \mathrm{C}$, although, even before melting, the grain-boundary phase had already facilitated deformation by enhancing diffusivity. ${ }^{24}$ In all cases, ductility of the ceramics, as well as other important mechanical properties (strength, toughness, hardness, and stability against moisture), was not impaired by the small amount of additives.

Note that zirconia ceramics usually contain a ceratin amount of Si impurity, which is localized at the grain boundaries. ${ }^{46} \mathrm{~A}$ ternary eutectic between zirconia, yttria, and silica exists at $1350^{\circ} \mathrm{C}$. Most likely the addition of $\mathrm{Mn}, \mathrm{Fe}$, and $\mathrm{Zn}$ has lowered the eutectic temperature. In the case of $\mathrm{Cu}$, it is reported that a binary eutectic of copper(ii) oxide (or copper(i) oxide) and zirconia lies between $1100^{\circ}$ and $1150^{\circ} \mathrm{C}$, depending on the oxygen potential. ${ }^{47}$ This report is consistent with the better sinterability and superplastic formability of this class of ceramics; namely, "undoped" Y-TZP becomes superplastic above $1350^{\circ} \mathrm{C}$, doped $Y$-TZPs are superplastic at $1250^{\circ} \mathrm{C}$, whereas $\mathrm{Cu}$ doping lowers the forming temperature further to $1150^{\circ} \mathrm{C}$.

It is remarkable that all $Y$-TZP ceramics are superplastically formable, as demonstrated in Fig. 1. (Formability will be discussed in more detail in Section IV.) Apparently, there is no loss of grainboundary strength despite a thin grainboundary layer of amorphous or even liquid phase, which is the result of unintended source/process contamination or deliberate doping. In this context, note that the characteristic dihedral angles measured at triple points between various zirconia phases are always quite distinct (Fig. 7). This distinction indicates that their respective interfacial energies are well-defined. We then conclude that the presence of a thin grain-boundary phase in Y-TZP ceramics does not dispel the classical notion of interfacial and like energies, ${ }^{36}$ and that even "contaminated" grain boundaries can have excellent strength and cavitation resistance.

Thus, the following major conclusions concerning superplastic material development can be made from zirconia studies. 
(i) The selection of an appropriate crystalline phase is often important for achieving an ultrafine grain size in single-phase ceramics. Tetragonal zirconia is a superior superplastic ceramic whereas cubic zirconia is not.

(ii) Both static grain growth and dynamic grain growth are closely related to the grain-boundary mobility. In tetragonal zirconia, segregating dopants are much more effective in suppressing static grain growth than dynamic grain growth.

(iii) Solute segregation has an added benefit in lowering grain-boundary energy and, correspondingly, strengthening the grain boundary.

(iv) The grain-boundary amorphous second phase, containing $\mathrm{Si}, \mathrm{Zr}, \mathrm{Y}, \mathrm{O}$, and most of the heavier transition-metal cations of the third row, is very effective in lowering the superplastic flow stress and increasing the deformation rate without lowering the grain-boundary cohesive strength.

\section{(2) Alumina}

There have been several unsuccessful attempts in the past to develop superplastic alumina. ${ }^{16.48-52}$ However, the tensile ductilities reported in these studies were all much lower than that found in zirconia. Recently, we have succeeded in superplastically stretching alumina (doped with 200 ppm magnesia) to large strains. ${ }^{13} \mathrm{~A}$ disk so formed is shown in Fig. 1, and its microstructure is illustrated in Fig. 3(b).

Although large-strain superplasticity is now possible, difficulties encountered in the course of developing superplastic alumina did provide valuable lessons to our current thinking about superplasticity in ceramics. These difficulties are related to processing, the use of additives, and their consequences on microstructural development and superplastic characteristics.

Unlike the case of Y-TZP, special attention must be paid to alumina powder processing. Because sintering alumina below $1300^{\circ} \mathrm{C}$ requires considerable skill and effort, 53 and grain growth above $1300^{\circ} \mathrm{C}$ is rather fast, only a very narrow processing window is available for this ceramic. The window may be widened somewhat by the use of additives that suppress grain growth, by hot-pressing, and by improving powder processing to allow densification at lower temperatures. Unfortunately, we have found magnesia ineffective in further lowering of the graingrowth rate in very-fine-grained alumina sintered below $1300^{\circ} \mathrm{C}$. As for hotpressing, results of previous studies seem to place a lower bound of about $1 \mu \mathrm{m}$ for the grain size of alumina, $43.50,54$ which is not fine enough for superplastic applications. Thus, low-temperature sintering is the only alternative.

From a processing viewpoint, the main obstacles for low-temperature sintering of ceramic powders are hard agglomerates in the powders and poor packing in the green body. 53.55.56 Powders often contain hard agglomerates which later sinter at different rates and inhibit shrinkage of the matrix by exerting a mechanical constraint. Poor packing of powders lowers the green density, which often delays sintering and leaves behind flaws. ${ }^{56}$ These problems can largely be avoided by meticulous handling of powders. This entails breaking up hard agglomerates in the starting powders, manipulating and controlling interparticle forces in the colloidal powder suspension, and direct consolidation of the slurry into a green body using colloidal pressing or pressure filtration techniques. ${ }^{56}$ The resultant homogeneous green compact, with a higher density and fewer defects and agglomerates, has a markedly improved sinterability. This can facilitate low-temperature sintering and the attainment of very fine microstructures.

Low-temperature sintering of pure alumina at $1150^{\circ} \mathrm{C}$ has been reported using special classified powders of a very fine particle size. ${ }^{53}$ In this case, the grain size at $99 \%$ of theoretical density is $0.25 \mu \mathrm{m}$. The yield of this type of processing, however, is too low for the purpose of laboratory testing of superplastic formability. Using unclassified powders and colloidal processing techniques, we have been able to sinter pure alumina at a temperature of $1250^{\circ} \mathrm{C}$. The microstructure of a sintered pure alumina is shown in Fig. 9(a). The grain size is as fine as $0.5 \mu \mathrm{m}$ and remains relatively stable during annealing at temperatures below $1300^{\circ} \mathrm{C}$

Pure alumina of such a grain size has a very low initial flow stress. However, it fails to deform superplastically because of rapid dynamic grain growth, which causes strain hardening (see Fig. 9(b) for the deformed microstructure and Fig. 10 for the stress-strain curve). Note that grains of a larger size in the deformed microstructure tend to be elongated. This is a general feature of grain growth in alumina and may be attributed to the anisotropy in grain-boundary energy. ${ }^{57}$ Large grains of this type serve as stress concentrators and potent nucleation sites for cavitation, thus degrading the ductility. A higher deformation temperature only exacerbates the problems, as shown in Fig. 9(c).

A fundamental problem associated with pure alumina is its relatively high grain-boundary energy. In addition to providing a higher driving force for grain growth, the high energy may also cause the grain boundary to have a relatively low cohesive strength, according to the argument advanced in the previous section. The direct evidence for a higher grain-boundary energy is once again provided by dihedral angle measure. ments, and the results are illustrated in Table $I$ and Fig. 11. In this case, an alumina/zirconia two-phase microstructure is used to establish the ratio of the 


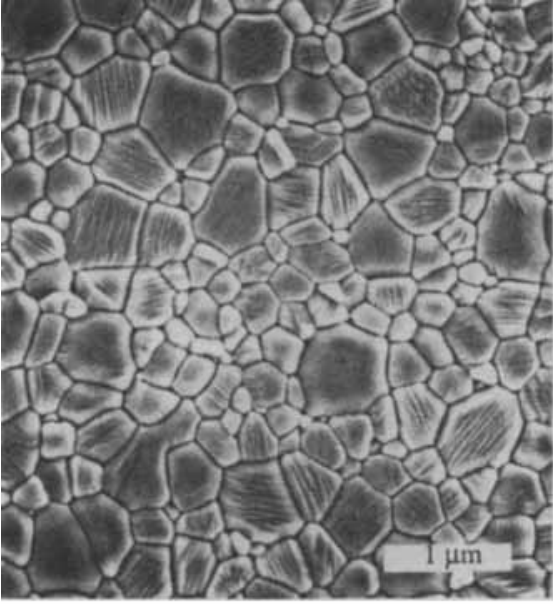

a

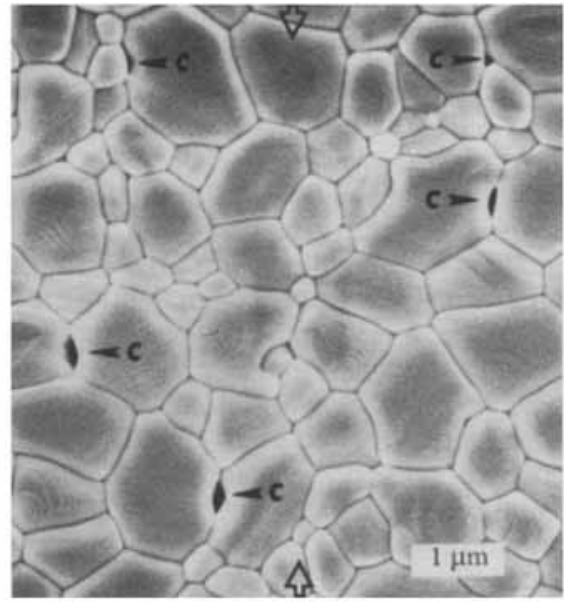

b

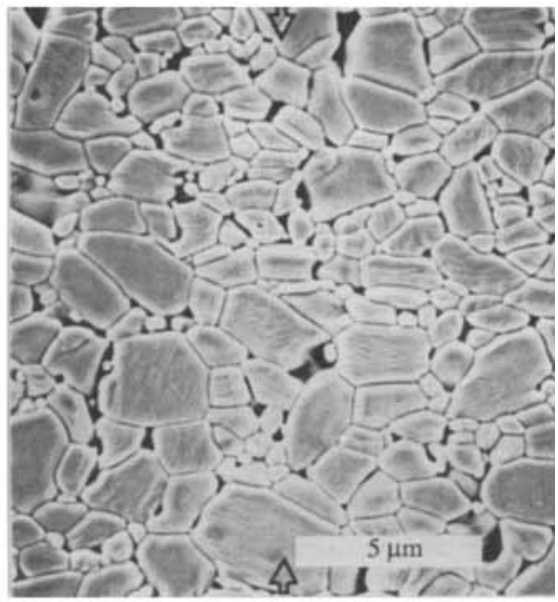

C

Fig. 9. Microstructure of pure alumina: (a) as sintered at $1250^{\circ} \mathrm{C}$; (b) deformed in compression at $1250^{\circ} \mathrm{C}$ (strain rate of $1.5 \times 10^{-5} \mathrm{~s}^{-1}$; total strain of 0.3 ) with compression axis shown by hollow arrows and cavities by solid arrows; and (c) same as (b) but deformed at $1400^{\circ} \mathrm{C}$ (strain rate of $2.4 \times 10^{-4} \mathrm{~s}^{-1} ;$ total strain of 0.68 )

grain-boundary energies of alumina $\left(\gamma_{a a}\right)$ and zirconia $\left(\gamma_{t t}\right.$ and $\left.\gamma_{c c}\right)$ to the interfacial energy between the two $\left(\gamma_{a t}\right.$ and $\left.\gamma_{a c}\right)$. The ratio reveals that the grain-boundary energy of alumina is even higher than that of cubic zirconia, which is higher than that of 2Y-TZP, as noted previously. The interfacial energies follow the sequence $\gamma_{a a}, \gamma_{c c}, \gamma_{a c}, \gamma_{a t}, \gamma_{t t}$, from highest to lowest. As expected, pure alumina has a high propensity for cavitation, even in compression (see Figs. 9(b) and (c)).

We have already mentioned magnesia as an additive for grain-growth control. Segregation of magnesia and other additives in alumina is fairly well established and has been attributed to the elastic energy due to a size misfit. ${ }^{58}$ Unlike zirconia, however, alumina has very little

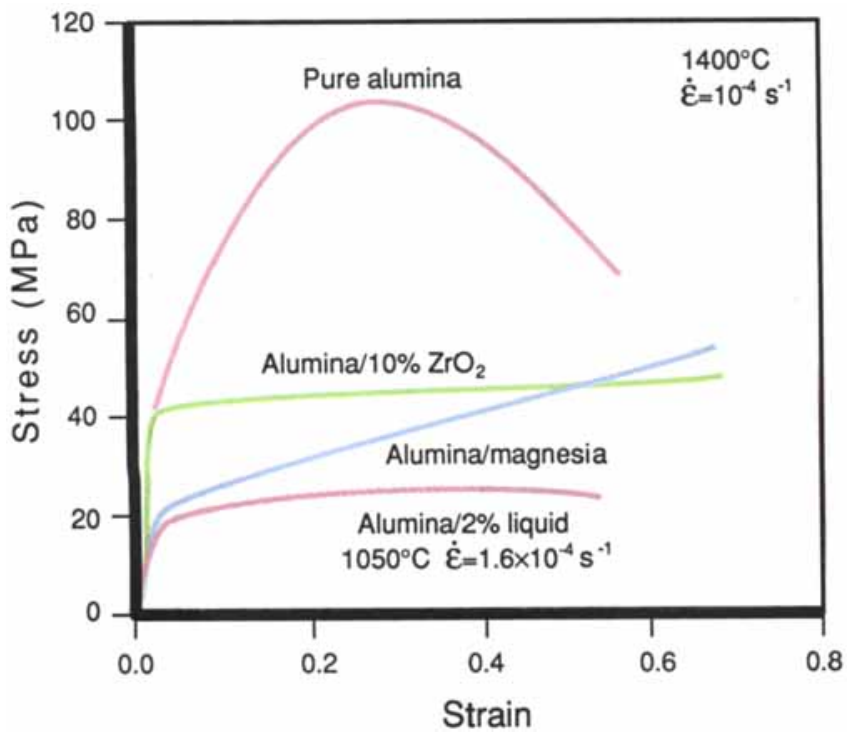

Fig. 10. Stress-strain curves for alumina. Strain hardening in pure alumina and magnesia-doped alumina is due to dynamic grain growth. The eventual decrease in stress in pure alumina is a result of cavitation. Note that alumina with $2 \%$ liquid was tested at a lower temperature. solubility for most aliovalent cations. For example, the solubility of magnesia at $1500^{\circ} \mathrm{C}$ is only $200 \mathrm{ppm} .59$ At such a low concentration and at low temperatures (below $1300^{\circ} \mathrm{C}$ ), magnesia has an unnoticeable effect on static grain growth. However, dynamic grain growth can be brought under control by the same amount of magnesia. This can be appreciated by comparing the stress-strain curve of pure alumina and $200 \mathrm{ppm}$ magnesia-doped alumina in Fig. 10. The relatively mild strain hardening of the latter is a direct consequence of the slower dynamic grain growth in this material. As demonstrated in Fig. 1, magnesia-doped alumina can be superplastically stretched to large strains.

Attempts have also been made to introduce a low-melting liquid phase (such as boron oxide and copper(II) oxide) and various charge-compensating dopant pairs (such as $\mathrm{Cu}^{2+}$ and $\mathrm{Ti}^{4^{+}}$) to alumina to lower the sintering and superplastic forming temperatures. These ceramics have very fine grains and they can be sintered and deformed at temperatures around $1050^{\circ} \mathrm{C}$. The resultant stressstrain curve is shown in Fig. 10. However, deformation is accompanied by abnormal growth of some grains. The cause for abnormal grain growth in this case is probably again associated with the anisotropy of grain-liquid interfaces. Moreover, the tensile ductilities are disappointing for these specimens, reaching only $15 \%$. These low ductilities indicate a severely degraded grainboundary cohesive strength, which is further compounded by the stress concentrations around abnormally large and elongated grains.

Thus, the following major conclusions are made from the above data for superplastic alumina.

(i) Because of its high and anisotropic 
grain-boundary energy, pure alumina is weak along the grain boundary and is prone to rapid, abnormal grain growth, making it an inherently difficult choice for ceramic superplasticity.

(ii) The use of additives is less effective for alumina than that for zirconia because of the limited solubilities of nearly all the cations. This results in the relatively weak grain-boundary cohesion observed in most cases to date.

(iii) Although magnesia is not necessarily needed for effecting low-temperature sintering, it does lower the grain-boundary mobility in dynamic grain growth. This has made large-strain superplastic stretching possible.

(iv) As the liquid phase lowers the flow stress of alumina, it also facilitates abnormal grain growth and probably lowers the interfacial strength. Superplasticity of alumina at low temperatures (below $1350^{\circ} \mathrm{C}$ ) thus appears unlikely, except in composites.

\section{(3) Silicon Nitride}

Two superplastic silicon nitrides have been reported recently. A fine-grained silicon nitride/silicon carbide composite (20 $w t \%$ silicon carbide) containing a variety of other mixed phases was deformed in tension to $150 \%$ at $1600^{\circ} \mathrm{C}$ and a strain rate of $4 \times 10^{-5} / \mathrm{s} .{ }^{21}$ Another silicon nitride, ${ }^{20}$ shown in Fig. 1, was punchstretched at $1500^{\circ} \mathrm{C}$. The microstructure of the latter is shown in Fig. 3(c).

In ceramic alloy design, there is a close analogy between silcon nitride and the two other ceramics discussed in the previous sections. Like zirconia, two polymorphs, $\alpha$ - and $\beta$-silicon nitride, exist which transform from one to the other by reconstruction. Both phases have a large range of solubility. The $\alpha$-phase solid solution can be represented as $\mathrm{M}_{z / n} \mathrm{Si}_{6-x-z} \mathrm{Al}_{x+z} \mathrm{O}_{x} \mathrm{~N}_{8-x}$ and is commonly referred to as $\alpha^{\prime}$-sialon in this form. 60 Here $M$ is a cation of a valence $n$ and of an appropriate ionic radius. The $\beta$-phase solid solution can be represented at $\mathrm{Si}_{6-x} \mathrm{Al}_{x} \mathrm{O}_{x} \mathrm{~N}_{8-x}$ and is referred to as $\beta^{\prime}$-sialon in this form. ${ }^{61}$ Both phases are derived from the respective $\alpha$-or $\beta$-silicon nitride unit cell by partial replacement of $\mathrm{Si}^{++}$by $\mathrm{Al}^{3^{+}}$. Valence compensation is by substitution of $\mathrm{N}^{3-}$ or $\mathrm{O}^{2-}$ and, in the case of $\alpha^{\prime}$-sialon, by additional modifier cations occupying the interstices of the $(\mathrm{Si}-\mathrm{Al})-(\mathrm{N}, \mathrm{O})$ network similar to that of the stuffed derivatives of silica. 62 Similar to alumina, $\beta^{\prime}$-silicon grains have a strong tendency for anisotropic grain growth at higher temperatures. They typically assume a needlelike morphology, and the growth mechanism involved has been identified previously. ${ }^{63}$ in contrast, $\alpha^{\prime}$-sialon grains tend to be small and equiaxed over a wide range of temperature, even though its crystal structure is highly anisotropic. 60

To sinter both sialons, metal oxides are often added as liquid-phase sintering aids. 64 This enhances densification and facilitates the conversion of the starting powders to the final, alloyed phases of the intended compositions. The amount and the composition of the liquid, as well as those of other phases, undergo continuous changes as sintering and annealing proceed.64 Because metal cations can be incorporated into the $\alpha^{\prime}$-sialon, it is theoretically possible to obtain a single-phase $\alpha$-sialon without any remaining liquid phase. This is not the case for $\beta^{\prime}$-sialon, which has no solubility for any cations other than $\mathrm{Si}^{+*}$ and $\mathrm{Al}^{3+}$.

The superplastic silicon nitride shown in Figs. 1 and 3(c) was designed to form $\alpha$-sialon.20 A small amount of crystalline yttrium aluminum garnet and $\alpha$-silicon nitride also exist in the final phase assemblage at $1500^{\circ} \mathrm{C}$. The amount of the liquid phase that exists during forming is relatively small. This ceramic maintains an equiaxed grain shape during superplastic forming. Because of the very fine and stable microstructure, this ceramic can be
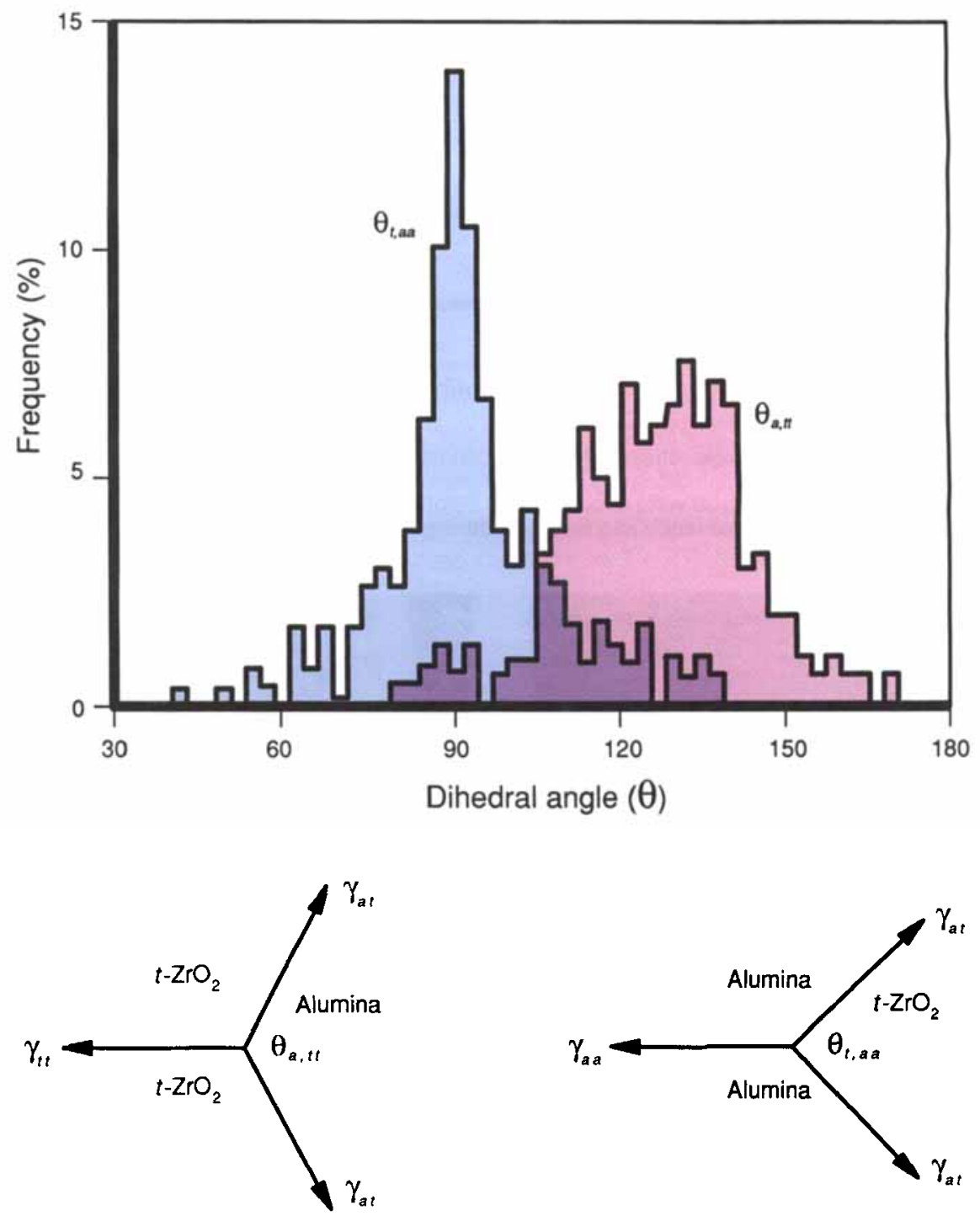

Fig. 11. Examples of distributions of dihedral angles between alumina and tetragonal zirconia. The peak values are given in Table I. Also shown schematically is the relationship between di. hedral angles and interfacial energies. 
deformed at a relatively low temperatures. The presence of the liquid phase lowers the flow stress still further. As shown in Fig. 12, only a mild strain hardening is apparent in superplastic deformation. The deformed microstructure, containing mostly equiaxed, fine grains, is shown in Fig. 13(a).

Wakai et al. took a different approach to developing a superplastic silicon nitride.21.22 They added silicon carbide to silicon nitride in the hope that grain growth would be suppressed. In addition, they used an amorphous Si-C-N powder to fabricate a hot-pressed composite in the hope that the initial grain size would be minimized. However, the composition

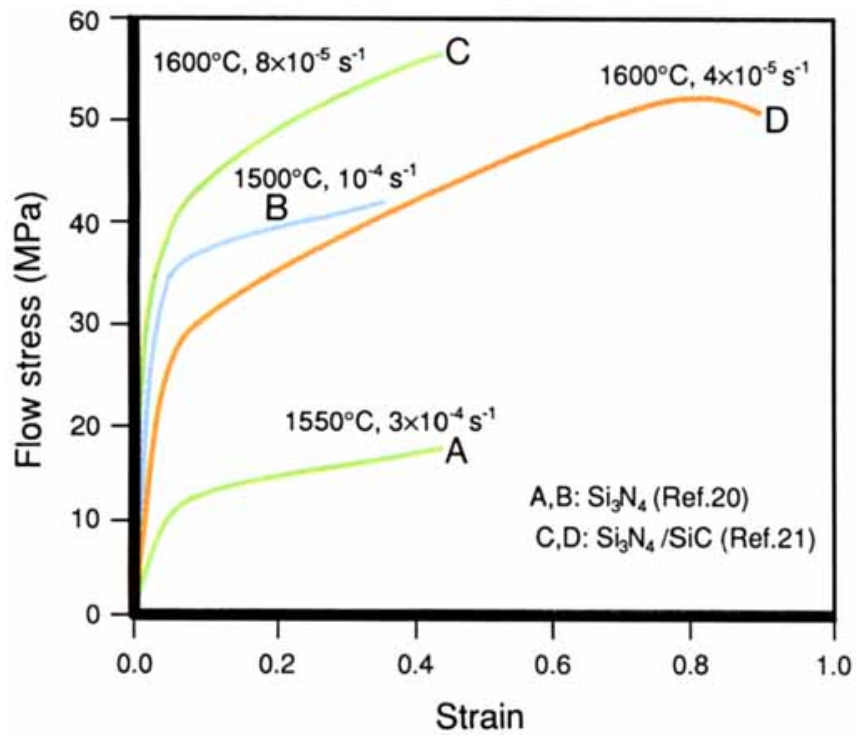

Fig. 12. Stress-strain curves of silicon nitrides, where $A$ and $B$ are mostly $\alpha^{\prime}$-sialon deformed in compression, 20 and $C$ and $D$ are mostly $\beta^{\prime}$-sialon with 30 vol\% silicon carbide deformed in tension. 21 Note that $A$ and $B$ have much less strain hardening than $C$ and $D$.

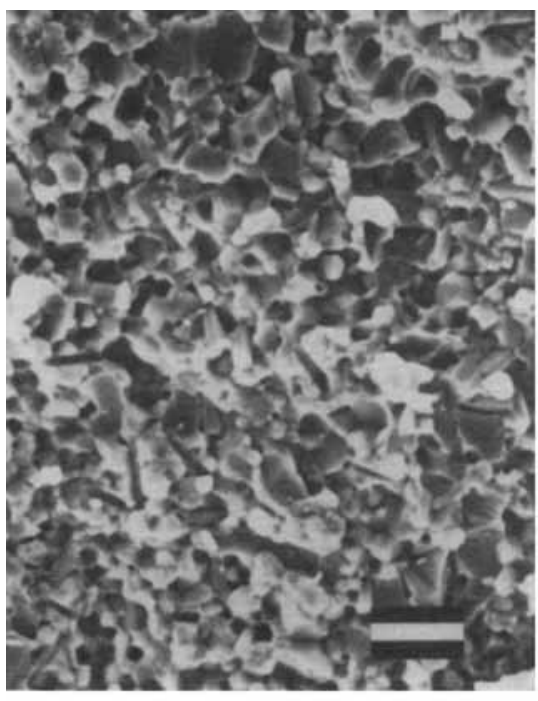

a

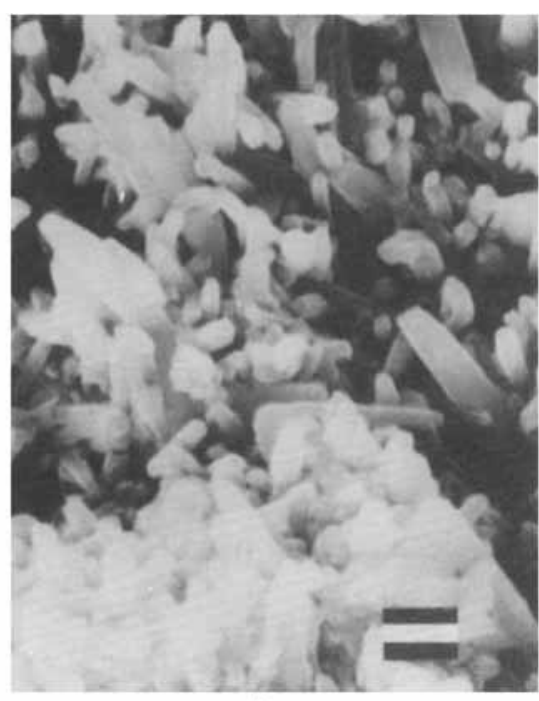

b
Fig. 13. (a) Microstructure of a deformed silicon nitride containing mostly $\alpha^{\prime}$-sialon (bar $=1 \mu \mathrm{m}$ ) Note similarity with Fig. 3 (c) due to the absence of anisotropic grain growth. (b) Microstructure of a deformed silicon nitride containing mostly $\beta^{\prime}$-sialon and 30 vol\% silicon carbide $(b a r=1 \mu \mathrm{m})$, showing much grain growth during deformation. of this silicon nitride was such that $\beta$ '-silicon nitride was the predominant phase, which began to develop an elongated grain shape in fabrication.22 The sintering aids added (yttria and alumina) provided a considerable amount of liquidphase and other phase mixtures which evolved with time. Although this silicon nitride can be deformed above $1600^{\circ} \mathrm{C}$, strain hardening is prominent, possibly because of the anisotropic grain growth of $\beta^{\prime}$-sialon.21,22 The higher deformation temperature also dictates that a severe weight loss occurs because of vaporization of silica from the liquid phase, and from nitrogen decomposition. Despite these problems, a large tensile ductility exceeding $150 \%$ was achieved, although the weight loss has caused deterioration of the surface finish. 21 A comparison of the stress-strain curves and deformed microstructures of the above two superplastic silicon nitrides is shown in Figs. 12 and 13. It is evident that the flow stress of $\alpha^{\prime}$-sialon is much lower than that of $\beta^{\prime}$-sialon/silicon carbide and that the microstructure of the former is much finer.

Thus, despite the substantially different phase compositions, amounts of the liquid, strain-hardening rates, microstructures, and deformation characteristics, large ductilities seem obtainable in several families of fine-grained silicon nitrides. This suggests that the $(\mathrm{Si}, \mathrm{Al}, \mathrm{O}, \mathrm{N})$ liquid present, partially modified by yttrium and possibly other cations, is available for superplastic stretching in that the liquid provides an adequate plastic deformation stability and cavitation resistance to prevent strain localization and fracture. Although further research is required to establish the optimum composition of the liquid and the lower limit of its amount for superplastic forming, these initial findings and their implications are indeed encouraging.

The following major conclusions regarding the development of superplastic silicon nitride are made.

(i) Obtainable through judicious phase and compositional control, equiaxed finegrained silicon nitride in the form of $\alpha$-silicon nitride and $\alpha^{\prime}$-sialon are resistant to static and dynamic grain growth. In contrast, $\beta$-silicon nitride and $\beta^{\prime}$-sialon are prone to anisotropic grain growth during forming, particularly at higher temperatures, which causes severe strain hardening.

(ii) The liquid phase in silicon nitride, containing $\mathrm{Si}, \mathrm{Al}, \mathrm{O}, \mathrm{N}, \mathrm{Y}$, and possibly additional cations, has adequate cohesive strength to resist cavitation in superplastic forming.

(iii) Silicon nitrides are excellent candidates for superplastic forming at intermediate temperatures, around $1500^{\circ} \mathrm{C}$. At higher temperatures, weight loss from liquid vaporization becomes severe and the surface quality deteriorates. 


\section{(4) Composites}

Composites of zirconia/alumina ${ }^{16.65}$ and zirconia/mullite ${ }^{17.18}$ have been investigated throughout the entire range of composition. Y-TZP with up to $80 \mathrm{vol} \%$ of alumina or mullite are superplastic and have very good formability. ${ }^{19}$ Pure alumina is also superplastic, under optimal conditions. Pure mullite has not been made superplastic as of this date.

Compared with monolithic ceramics, composites have the distinct advantage of superior microstructural stability against both static and dynamic grain growth. The as-sintered composites usually have a smaller grain size, even though they may require a higher sintering temperature than those of the monolithic ceramics made of either constituent. In particular, a duplex microstructure can be obtained, i.e., one in which two phases are of nearly equal volume fraction and are both multiply connected. Known for its fine grain sizes and excellent resistance against coarsening, many such microstructures have figured prominently in the historical development of superplastic metallic alloys (e.g., $\mathrm{Pb}-\mathrm{Sn}$ and $\mathrm{Zn}-\mathrm{Al}$ alloys, $\alpha-\beta$ brass, $\alpha-\beta$ Ti alloys, and $\alpha-\gamma$ stainless steel). ${ }^{2}$ Duplex microstructures have also been obtained for zirconia/mullite and zirconialalumina composites. An example of the latter is shown in Fig. 3(d) with a grain size of about $0.2 \mu \mathrm{m}$. Sintered in the temperature range of $1370^{\circ}$ to $1480^{\circ} \mathrm{C}$, these duplex composites can maintain their very fine microstructures even after large superplastic deformation, provided that the deformation temperature does not exceed the sintering temperature.

Considerable microstructural stability is already evident when the second phase is present at a smaller volume fraction, typically no more than $20 \%$. This improvement is especially important for dynamic grain growth. A striking example is encountered in alumina with zirconia inclusions. Although fine-grained pure alumina is subject to rapid dynamic grain growth, its grain size remains largely stable during superplastic deformation when 10 vol\% zirconia is added. This addition of zirconia also suppresses (or eliminates) strain-hardening behavior, as shown in Fig. 10, thus improving the superplastic formability of this material.

From a microstructural control view point, there is an important relationship between the matrix grain size and the size or amount of the second-phase particles. Since the early work of Zener, ${ }^{66}$ the particle-pinning effect has been of continuing interest. Superplastic ceramic composites offer an opportunity to reexamine this effect in ultra-fine-grained ceramics. According to the analysis of Hellman and Hillert, 67 the matrix grain size, $d$, is 1.8 times that of the particle size, $r$, normalized by the cube root of the volume fraction, $v$. This is equivalent to having 6 pinning particles, on average, for every grain. In this model, grains are pinned in three dimensions by particles residing on grain corners.

Data from fine-grained zirconia/mullite and zirconia/alumina, for a volume fraction of the second phase between $1 \%$ and $15 \%$, are plotted in Fig. 14 to evaluate this prediction. Although some scattering does exist, these data can be reasonably correlated by the following equation:

$d=\alpha r / v^{1 / 3}$

where $\alpha$ is about 0.75 . This is equivalent to having 0.4 of a pinning particle for every grain. Since Hellman and Hillert's model assumes equilibrium and the prediction is for the limiting grain size, it is expected that the model has severely underestimated the pinning effect. This is especiaily so when low-mobility grain boundaries dominate, as should be the case in the best superplastic ceramics. From a practical point of view, the indication of a much stronger pinning effect than their model has suggested is certainly encouraging

The beneficial effect of a second phase on coarsening stability is largely lost when a significant amount of liquid phase is present. For example, adding silicon carbide to silicon nitride appears to have little effect on the growth of $\beta^{\prime}$-sialon grains (Fig. 13(b)), which assume a characteristically elongated shape.21 Growth of $\beta$ '-sialon grains probably proceeds via a solution-reprecipitation mechanism through the liquid phase aided by phase conversion in these ceramics. ${ }^{63,64} \mathrm{Be}$ cause particle coarsening is only weakly

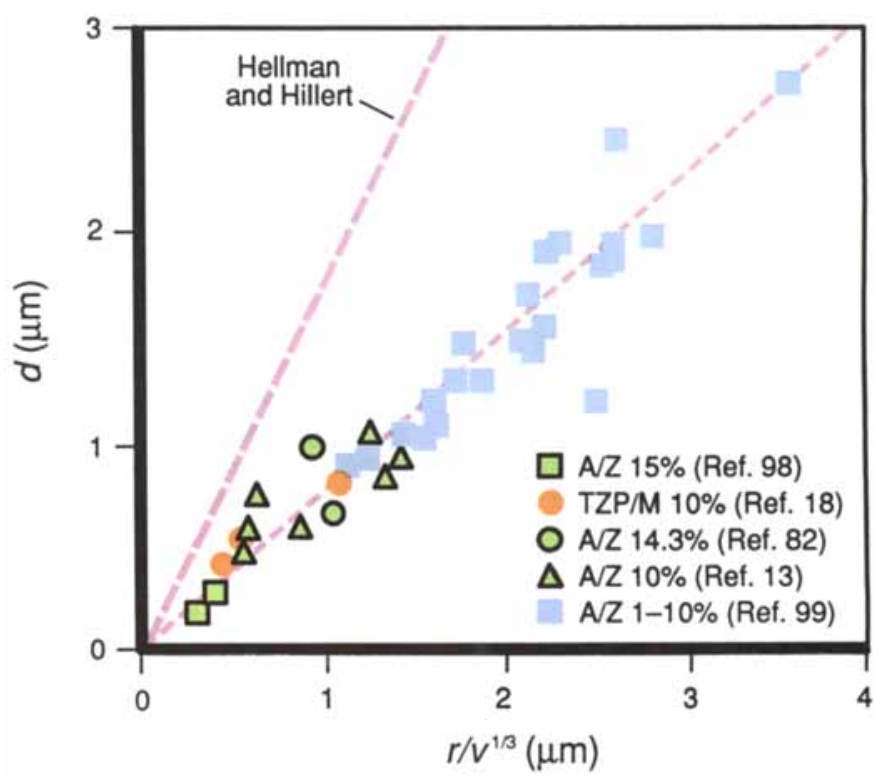

Fig. 14. Grain size $d$ as a function of inclusion size $r$ and volume fraction of inclusions $v$. The matrices are alumina $(A)$ and TZP. Inclusions are zirconia $(Z)$ and mullite $(M)$, with their volume fractions indicated. 
dependent on the volume fraction of the particulate phase itself, 68 the presence of another inert inclusion phase (silicon carbide) is not expected to have a major effect on the coarsening of silicon nitride. Experimental observations of considerable strain hardening in this material (see Figs. 12(c) and (d)), as well as the deformed microstructure reported (Fig. 13(b)), are consistent with the above expectation.

The following major conclusions regarding the development of superplastic ceramic composites are made.

(i) As in metals, ceramic composites with a duplex microstructure are essentially stable against static and dynamic coarsening at temperatures below that for sintering. These composites are excellent superplastic ceramics.

(ii) Composites with a modest amount of second phase gain considerable stability against static and dynamic grain growth. Thus, the grain size remains small after sintering and during forming and the material becomes superplastic. In alumina, for example, particle pinning renders the composite superplastic whereas pure alumina is not

(iii) When grain growth occurs by Ostwald ripening via solution, diffusion, and reprecipitation through a liquid phase, static and dynamic grain growth cannot be suppressed merely by the introduction of second-phase inclusions. Unless the primary phase is itself stable against coarsening, these composites have only a limited capacity for superplastic deformation.

\section{Deformation Characteristics}

Although there is general agreement that deformation mechanisms in superplasticity are similar to diffusional creep, ${ }^{3}$ definitive identification of specific mechanisms has not been successful. Reviews of data from superplastic metals reveal that, in several important aspects, superplasticity ${ }^{2.4-7}$ differs from diffusional creep. ${ }^{38}$ First, the grain shape change after large deformation is remarkably small, contrary to that envisioned in diffusional creep models. Second, the contribution from grain-boundary sliding is unusually large, compared with diffusional creep. Third, the stress and grain-size exponents are often substantially different from the prediction of simple diffusionat creep models. These discrepancies have motivated several models which modify the conventional descriptions of diffusional creep for superplastic applications. In particular, concepts such as grain switching, ${ }^{4}$ grain rotation, 5 and grain-shape transformation 6 have been introduced, and the enhanced roles of grain-boundary sliding and grainboundary migration have been proposed. Some also envision an interplay of diffusional processes and (grainboundary or lattice) dislocation processes. ${ }^{69,70}$ Despite these efforts, such models are largely qualitative and fail to quantitatively account for the observed deformation rate of superplasticity.

This state of the art dictates that the present discussion of deformation characteristics should be confined to comparisons based on the phenomenological constitutive equation (Eq. (1)). In the following, an analysis of the stress, grain size, and temperature dependence of deformation for several superplastic ceramics is first presented. The effect of a second phase is then rationalized based on continuum mechanics models and on interface-related considerations. Finally, the origin and the effect of dynamic grain growth on deformation characteristics are explored. We postpone the discussion of fracture to Section IV where superplastic formability is assessed.

\section{(1) Stress, Grain Size, and Temperature Dependence}

Our discussion of the stress, grain size, and temperature dependence in ceramic superplasticity is concentrated on $2 Y$ TZP and alumina, where the best and most complete data are available. Although 3Y-TZP has been widely studied, it contains some cubic grains which tend to grow larger in size over time, making a definitive analysis of the deformation characteristics more difficult. For comparison, diffusional creep data of $Y$-CSZ will also be reviewed. .1-74 $^{-1}$

In the absence of any intentionally added liquild phase, data for 2Y-TZP from different studies ${ }^{12,17.24 .75}$ are in reasonable agreement with each other when experiments conducted under similar deformation conditions are compared (see Fig. 15(a)). No significant grain growth is evident in 2Y-TZP at lower test temperatures. The stress exponent ranges from 1.5 to 2 , and is independent of temperature. Wakai has also reported an increasing stress exponent with decreasing grain size, ${ }^{12,75}$ a trend similar to the one observed in alumina. ${ }^{54}$ Data illustrating this trend, commonly associated with interface-controlled diffusional creep, ${ }^{54}$ are compiled in Fig. 16 and are discussed later. This trend is less obvious at higher stresses and strain rates. The grain-size exponent of $2 Y$-TZP ranges between 1 and 3 , according to the various reports in the literature. However, because the stress exponent can itself be a strong function of the grain size, the grain-size exponent may appear higher at higher stresses.

The above observations are analogous to fine-grained superplasticity in metals and alloys and are generally incompatible with dislocation creep. The following considerations further rule out dislocation creep as a major mechanism in ceramic superplasticity. Flow stress for dislocation motion is strongly dependent on the solute content in zirconia ceramics. ${ }^{76}$ if the available flow stress data of $Y$-CSZ ${ }^{76}$ are extrapolated to lower yttrium content, as 
appropriate for $Y-T Z P$, they are still much higher, by 1 or 2 orders of magnitude, than the superplastic flow stress shown in Fig. 15(a). This argument is also reinforced by the independent observation ${ }^{17}$ that the anticipated dislocation spacing $\lambda$, which should follow a universal scaling law, ${ }^{77} \lambda=2 \mathrm{~b} G / \sigma$, much exceeds that of the zirconia grain size in most cases, especially at higher temperatures. In this scaling law, $G$ is the shear modulus and $\mathbf{b}$ is the Burgers vector. The size of subgrains, if they do exist from regrouping of dislocations, would be even larger. ${ }^{77}$ Thus, lattice dislocation activities are not likely to be significant in superplastic zirconia, except at very high strain rates.

In the literature of superplastic metals and alloys, transitions between deformation regimes signified by a change of the stress exponent are well documented. ${ }^{2}$ In contrast, the transition from the superplastic regime (referred to as regime 11 in the superplasticity literature) ${ }^{2}$ to a dislocation regime (regime $\mathrm{III}$ ) is rarely seen in ceramics. This is primarily due to the fact that most ceramics do not have sufficient strength to resist fracture before the high flow stresses required for the transition can be reached. Moreover, no threshold stress (regime I) is evident in ceramics, at least over the stress range thus far investigated. Thus, ceramic superplasticity, as typified by the data shown in Fig. 15(a) for 2Y-TZP, apparently lies entirely in regime 11 .

The temperature dependence of Y-TZP follows an Arrhenius behavior, characterized by an activation energy ranging from 530 to $630 \mathrm{~kJ} / \mathrm{mol}, 12.17 .24 .75$ This value is somewhat higher than the activation energy of cation lattice diffusion in cubic zirconia. ${ }^{37}$ However, no diffusion data are currently available for any tetragonal zirconia. Note that activation energies for grain-boundary mobility of a variety of TZP, shown in Fig. 5, which is probably rate limited by lattice diffusion of cations in the space charge cloud, are also higher than the activation energy of ca-

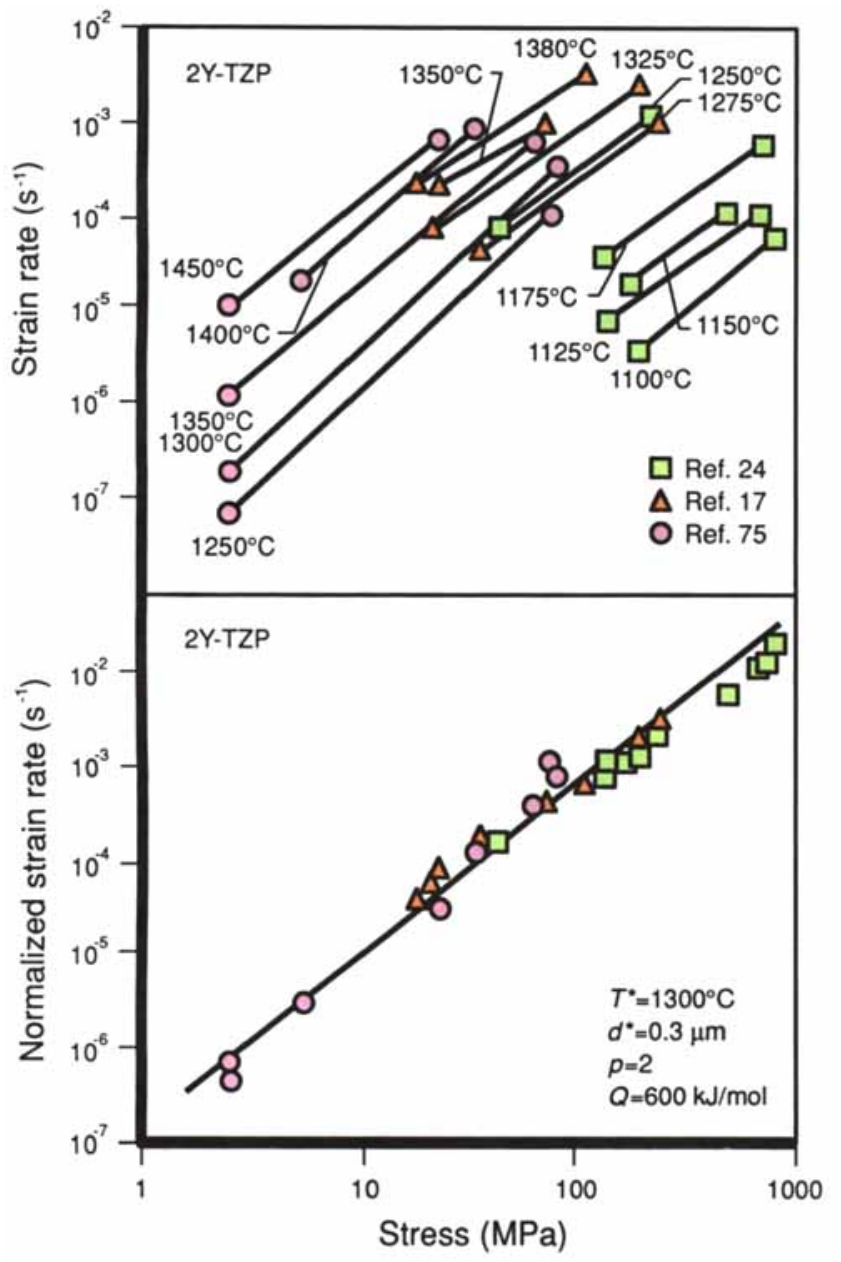

a

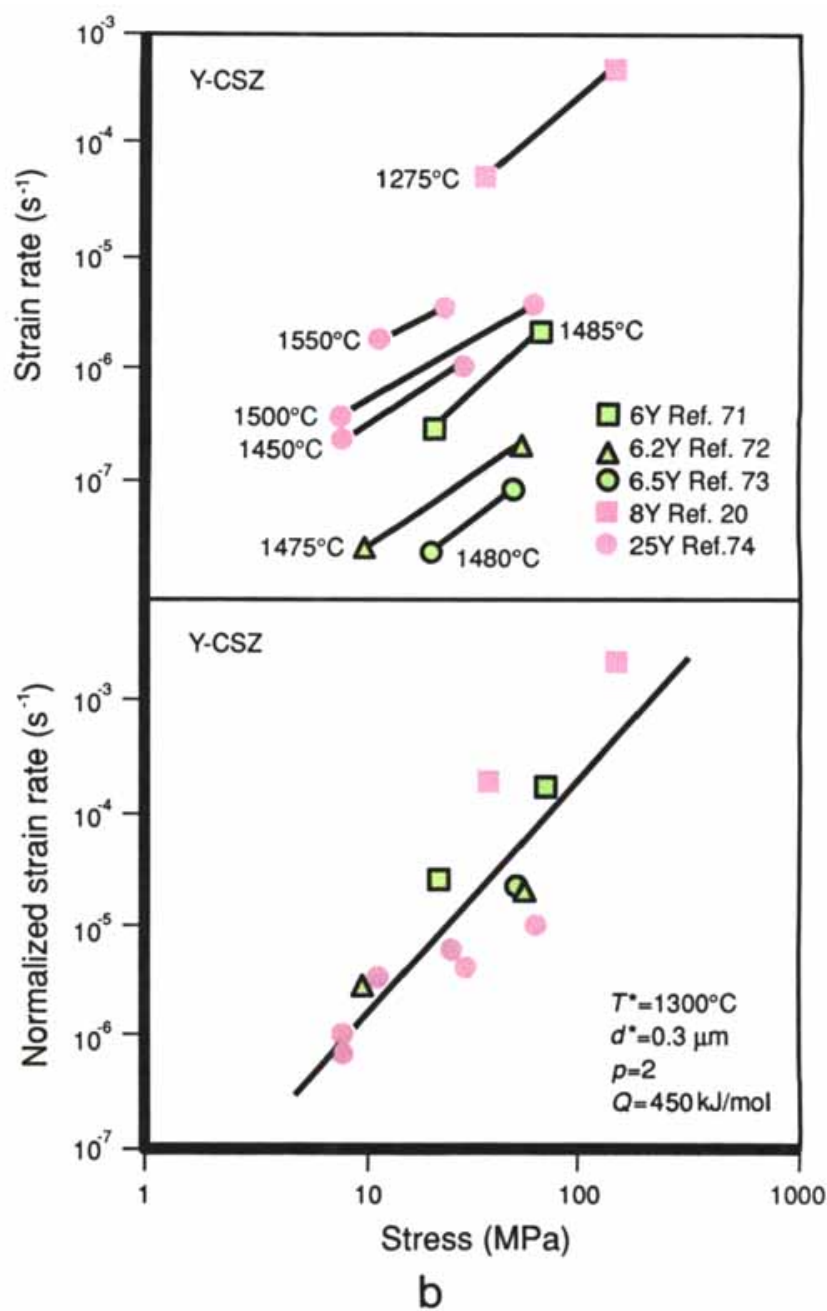

Fig. 15. (a) Relationship between strain rate and stress for $2 Y$-TZP. Grain size is $0.21 \mu \mathrm{m}$ for Ref. $24,0.39 \mu \mathrm{m}$ for Ref. 17 , and $0.48 \mu \mathrm{m}$ for Ref. 75. Grain sizes cited here are 1.56 times the average linear intercept distance between grain boundaries. Range of data for different forming conditions is indicated in the upper figure by symbols at the two ends of each line. Data are replotted in the lower figure after normalization to a reference temperature $T^{*}$ and a reference grain size $d^{*}$ using values of grain-size exponent $p$ and activation energy $Q$, as shown. Very good agreement between different data sets is apparent. (b) Relationship between strain rate and stress for Y-CSZ. Grain size for Ref. 71 is $17 \mu \mathrm{m}, \mathrm{Ref} .72$ is 17.5 $\mu \mathrm{m}$, Ref. 73 is $29 \mu \mathrm{m}$, Ref. 20 is $0.48 \mu \mathrm{m}$, and Ref. 74 is $2.6 \mu \mathrm{m}, 3.5 \mu \mathrm{m}$, and $4.2 \mu \mathrm{m}$ for $1450^{\circ}, 1500^{\circ}$, and $1550^{\circ} \mathrm{C}$, respectively. Compositions of yttria are indicated as well. When the data are normalized, as in Fig. 15(a), they fall on a single line. Data of the fine-grained Y-CSZ are comparable to those of $2 Y-T Z P$, shown in Fig. 15(a). 
tion lattice diffusion in cubic zirconia. ${ }^{36}$ However, a nonlinear stress dependence and the possibility of interface-controlled creep preclude a definitive interpretation of the activation energy.

Although deformation mechanisms of superplasticity are similar to diffusional creep, circumstances for interfacecontrolled deformation may arise when grain boundaries do not act as perfect sources and sinks for vacancies or they do not slide or migrate freely. ${ }^{78}$ In this case, the strain rate may increase nonlinearly with stress, and sometimes the materials may even exhibit a threshold deformation stress. For example, interface reactions involving dislocation glide or climb result in a quadratic dependence of strain rate on stress, ${ }^{79}$ whereas those involving nucleation may show an exponential dependence on stress. ${ }^{80}$ At smaller grain sizes, when diffusional creep is too fast to be equaled by interface reactions, the nonlinear stress dependence should be accentuated. Solute segregation or particle pinning may also hinder diffusional creep by restricting grain-boundary sliding or migration, which is generally necessary for grain-tograin accommodation. Similar circumstances for interface-controlled deformation may arise when a grain-boundary liquid is present. ${ }^{81}$

A detailed study of $2 Y-T Z P$ containing a copper-rich grain-boundary phase has demonstrated the transition behavior between various mechanisms. ${ }^{24}$ The stress exponent, grain-size exponent, activation energy, and the effect of the amount of copper(II) oxide, have been determined. From these data, it has been concluded that, in undoped $2 Y-T Z P$, deformation is controlled by grain-boundary diffusion. In doped 2Y-TZP, below the eutectic tem. perature, deformation is controlled by diffusion along the copper-rich grainboundary phase and is dependent on the amout of copper(II) oxide. Above the eutectic temperature, deformation is still enhanced by the liquid present, although the strain rate is now limited by interface reactions and independent of the amount of the liquid phase. The stress exponent increases and the grain-size exponent decreases when grain-boundary melting occurs. As shown in Fig. 17, this transition is rather abrupt and serves as a good indicator of the presence of a liquid-phase effect in superplastic ceramics, whereas the more gradual rise above the melting point can be attributed to interface reactions. A similar increase of the stress exponent with temperature occurs when a liquid phase is present in alumina. For example, when $2 \%$ liquid is added to pure alumina, $n$ increases from 1.1 at $1050^{\circ} \mathrm{C}$ to 1.5 at $1150^{\circ} \mathrm{C}$, as shown in Fig. 17. The deformation rate is enhanced greatly by the liquid (Fig. 10). Once again, interface reactions are suggested as the ratelimiting deformation mechanisms.

Substantially similar deformation characteristics have been observed for $3 Y$ TZP, although data from various reports are slightly more scattered. ${ }^{12,25-28}$ This is not surprising because of the compositional variations of commercial powders from different sources. Carry has documented such compositional effects ${ }^{28}$ on deformation behavior in two batches of 3Y-TZP, although further studies are still required to identify the critical elements (probably aluminum and silicon) which influence the flow stress and ductility. More interestingly, even 8Y-CSZ appears to deform at rates similar to those of 2Y-TZP at a comparable grain size and flow stress despite the difference in solute concentration and crystal structure. 20 However, in this case, superplastic deformation is

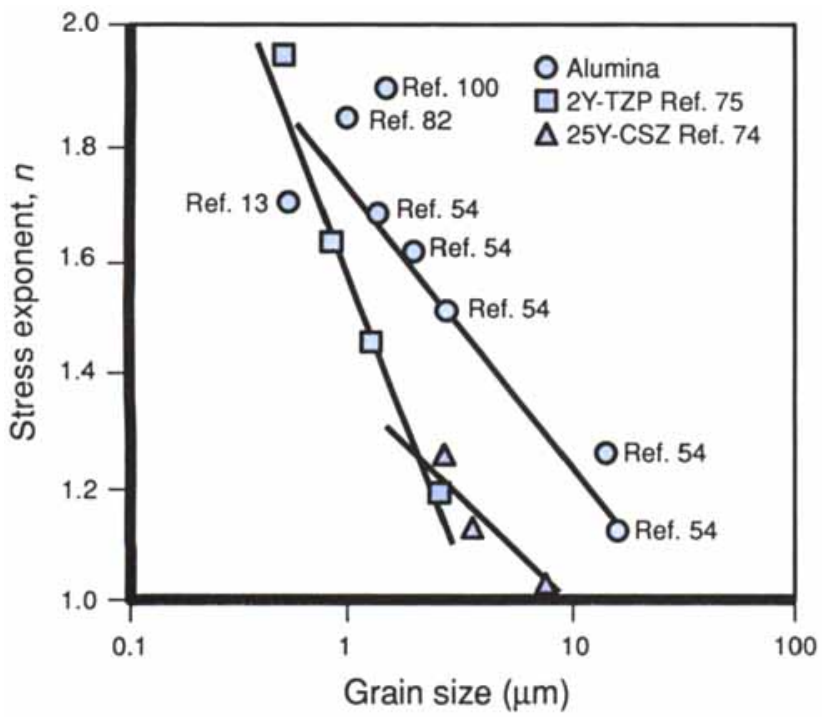

Fig. 16. Stress exponent versus grain size for three ceramics.

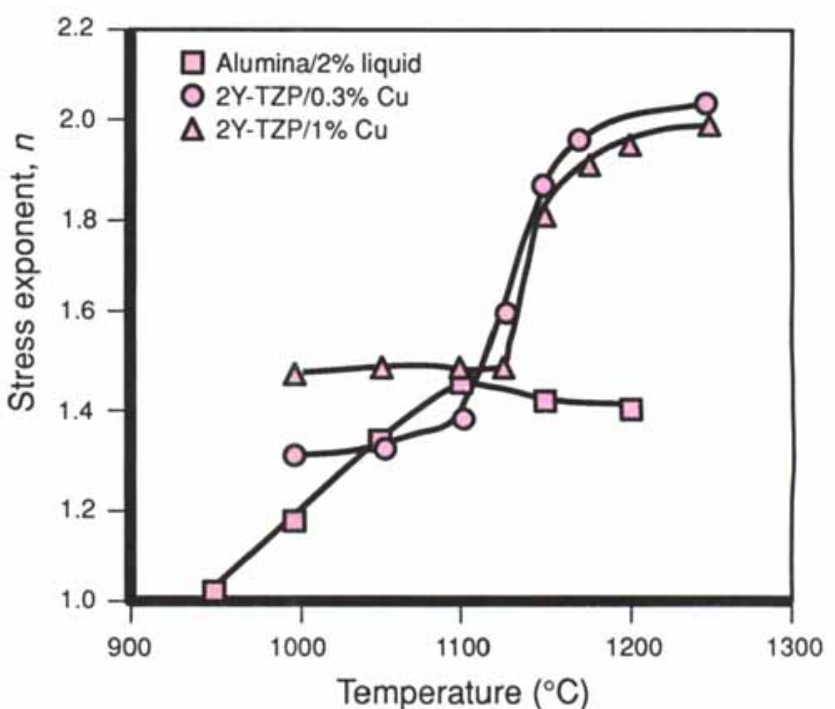

Fig. 17. Variation of stress exponent with test temperature. Abrupt increase in $2 Y-T Z P$ at $1130^{\circ} \mathrm{C}$ is due to melting of the grain-boundary phase. Melting temperature of the liquid in alumina is considerably lower. Gradual rise above the melting temperature is attributed to interface reactions in both cases. 
quickly overtaken by rapid static and dynamic grain growth and cavitation. The available data for other yttrium-stabilized cubic zirconia of much larger grain sizes and various compositions ${ }^{71-74}$ are also reasonably similar to that for $2 Y-T Z P$ when extrapolated to comparable grain sizes. These data are compiled in Fig. 15(b). Note also the tendency for the stress exponents to decrease with increasing grain size, as shown in Fig. 16.

The analysis of stress, grain size, and temperature dependence of the deformation data for fine-grained pure alumina, except perhaps at the lowest testing temperature, is complicated by dynamic grain growth. At higher temperatures, static grain growth also becomes prominent and adds to the complexity. However, if the initial strain rate values of fine-grained alumina ${ }^{13}$ are compared with the extrapolated values from largergrained alumina reported in the literature, ${ }^{54,82}$ then the values are generally in reasonable agreement as shown in Fig. 18. It may also be concluded from Fig. 18 that, when magnesia is intentionally added, it enhances the strain rate by a factor of 3 to 4 at most. Fortuitously, the flow stress of alumina happens to be of the same order of magnitude as that of Y-TZP and Y-CSZ of a comparabie grain size. The activation energy ranges from 450 to $530 \mathrm{~kJ} / \mathrm{mol} .13,54,82$

At a grain size of $0.5 \mu \mathrm{m}$ and temperatures between $1250^{\circ}$ and $1400^{\circ} \mathrm{C}$, deformation of alumina at low flow stresses is probably controlled by cation diffusion along the grain boundary, limited by interface reactions. 54 As evidence, the stress exponent is around 2 and decreases with increasing grain size as shown in Fig. 16, which is consistent with the interpretation of interface reactioncontrolled mechanisms. The interpretation of interface control in alumina is given further credence by the effect of a small amount of grain-boundary precipitates. When 1000 ppm of insoluble zirconia is added to an otherwise pure alumina, the creep rate is severely suppressed by a factor of about 20.82 Zirconia inclusions/particulates also raise the activation energy to around $750 \mathrm{~kJ} / \mathrm{mol}$, which is comparable with that found in alumina/zirconia composites. 65.82 Thus, although pure alumina deforms at about the same rate as $2 Y$-TZP of a comparable grain size, alumina may be considerably hardened in a zirconia/alumina composite. This is indeed the case, as discussed in the next section.

\section{(2) Effect of a Second Phase}

The effect of a second phase on superplastic deformation has been investigated using 2Y-TZP/mullite 17.18 and 3Y-TZP/alumina ${ }^{16,65}$ as model systems. Mullite composition in these studies is offstoichiometry, being rich in $\mathrm{Al}^{3+}$, to maintain an equiaxed grain/inclusion shape. In both cases, there is little mutual solu-

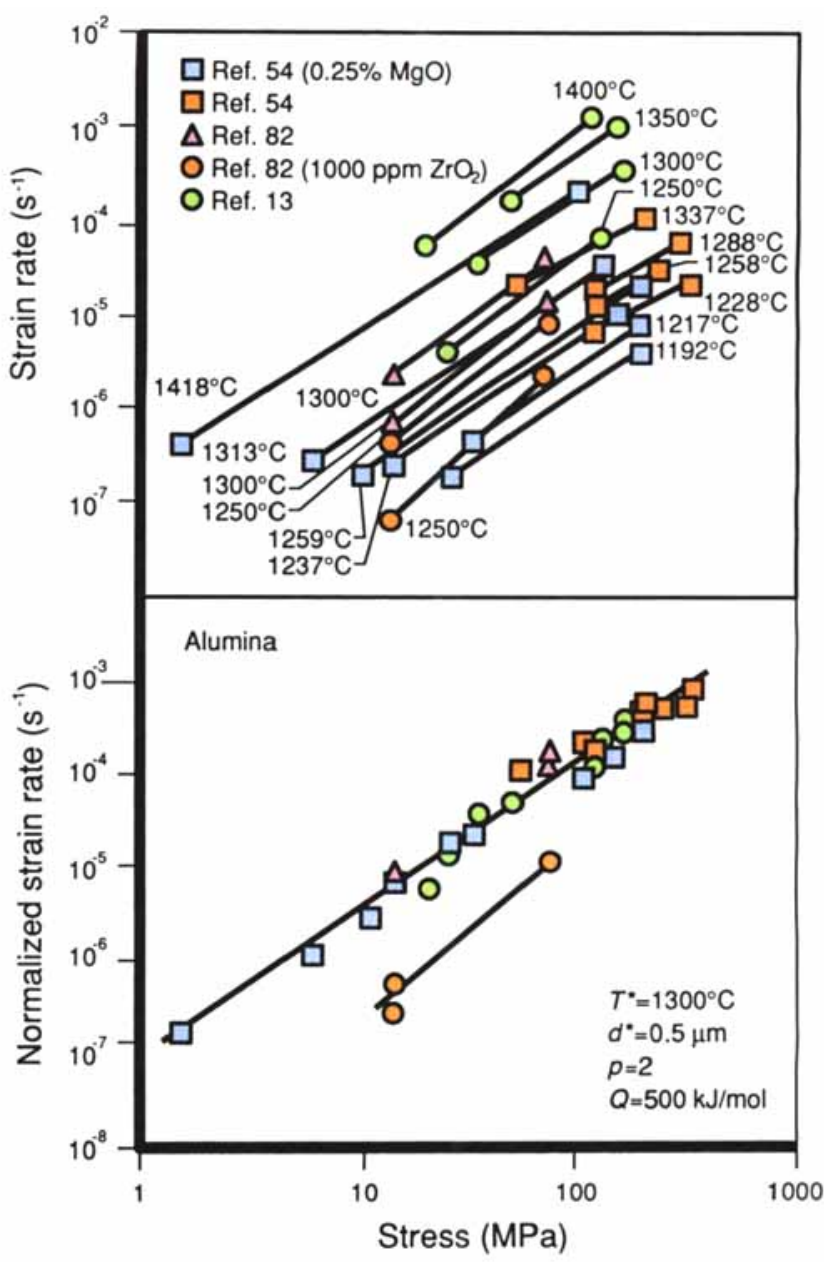

Fig. 18. Strain rate versus stress of alumina. Grain size for Ref. 54 is $1.25 \mu \mathrm{m}$ for both pure and magnesia-doped material, Ref. 82 is 0.96 $\mu \mathrm{m}$ without zirconia and $0.59 \mu \mathrm{m}$ with zirconia, Ref. 13 is $0.51 \mu \mathrm{m}$. Range of data for different forming conditions is indicated in the upper figure by the symbols at the two ends of each line. Grain sizes cited here are 1.56 times the average linear intercept distance between grain boundnaries. Data are replotted in the lower figure after normalization to a reference temperature $T^{*}$ and a reference grain size $d^{*}$ using values of grain-size exponent $p$ and activation energy $Q$, as shown. Very good agreement between different data sets is apparent

bility between constituent phases at the sintering and deformation temperatures. These composites are all superplastic, and may serve as model systems of a soft matrix (TZP) containing equiaxed, and presumably harder, inclusions (mullite and alumina). The particle shape effect of nonequiaxed hard inclusions on superplastic flow has also been considered in the literature ${ }^{17}$ but will not be further pursued here.

An essentially insoluble second phase can have two effects on deformation resistance of a fine-grained ceramic: (a) a modification of continuum deformation mechanics and (b) a change in interfacerelated deformation characteristics. The first effect can be understood by continuum mechanics, in that the deformation resistance of a composite may be determined entirely by knowing the deformation resistance of the constituent phases, after computing the appropriate 
stress and strain distributions in the twophase composite. ${ }^{6}$ The second effect is entirely microscopic, usually localized to grain boundaries and interfaces between phases, and arises from the alteration of the diffusion path, diffusion rate, and interface reactions due to chemical or structural modifications of the interface itself or of interfacial phases. Although the continuum effect becomes significant only at a substantial volume fraction-for example, $20 \% \%^{83}$ of the second phase-the microscopic effect can be very pronounced with only a trace amount of additives. Both effects have been observed in superplastic ceramics, and in some cases concurrently, as will be discussed later in this section.

At $1350^{\circ} \mathrm{C}$, the flow stress of mullite is 2 orders of magnitude higher than that of $2 \mathrm{Y}-\mathrm{TZP}$ of a comparable grain size.17.18.84 Hence, mullite inclusions in 2Y-TZP can be considered rigid. For such a composite, a continuum model, which pictures the composite flow as a nonNewtonian fluid containing rigid particulates, is appropriate.6,17 The prediction of this rheological model is

$\dot{\varepsilon}=\dot{\varepsilon}_{0}(1-v)^{2+n / 2}$

where $v$ is the volume fraction of the rigid inclusions, $\dot{\varepsilon}_{0}$ is the strain rate of the reference matrix (taken as the one with an identical grain size but without inclusions), and $\dot{\varepsilon}$ is the strain rate of the composite. Experimental data for $2 Y-T Z P$ containing up to 80 vol\% mullite, shown in Fig. 19, are in very good agreement with this model if mullite is considered to be a rigid, included phase.

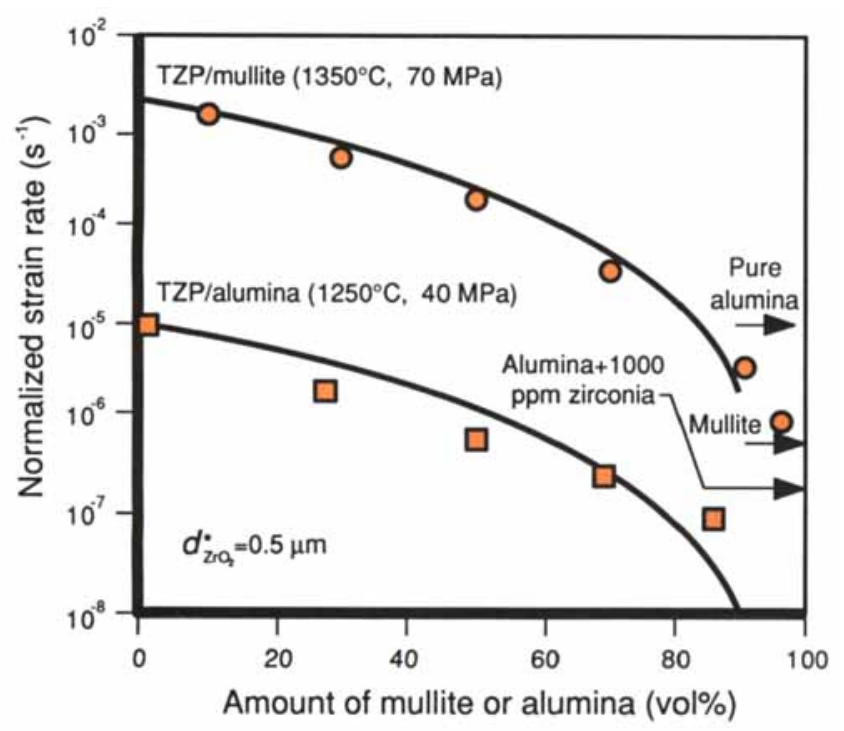

Fig. 19. Strain rate as a function of volume fraction of mullite or alumina in two TZP matrices deformed at the same flow stress. Strain rate data have been normalized, using the matrix grain size, to $d^{*}$. Also indicated on the right are the strain rate of pure alumina, mullite, and alumina with $1000 \mathrm{ppm}$ zirconia, all at a comparable grain size. Two solid curves are predictions of the rheological model, assuming that mullite and alumina form rigid, equiaxed inclusions. Data for TZP/mullite are from Ref. 18, and for TZPlalumina from Refs. 40 and 65.
Deformation data for 3Y-TZP containing up to 70 vol\% alumina, shown in Fig. 19 , are also well described by the rigid inclusion model. This is surprising, however, because pure alumina has a deformation resistance comparable with that of $3 Y-T Z P$, as noted previously. This apparent contradiction becomes explicable if we also recall that even a little zirconia impurity (1000 ppm) can severely reduce the deformation rate of alumina. Therefore, although pure alumina is no harder than $3 Y$-TZP, alumina in a zirconia matrix should behave similar to rigid inclusions, consistent with the data in Fig. 19. The continuum rheological model with rigid, equiaxed inclusions has thus been verified in superplastic flow of Y-TZP with both mullite and alumina as a second phase.

The effect of a second phase on the microscopic level is already exemplified by the dramatic hardening of pure alumina with a small addition of zirconia ${ }^{82}$ This is most likely due to the suppression of interface reactions or hindrance of grain-boundry movement by intergranular zirconia precipitates. Unlike alumina, mullite does not experience such an anomalous hardening effect caused by zirconia additions. On the other hand, small additions of zirconia progressively and substantially reduce the deformation resistance of mullite, ${ }^{18}$ as evident from the data shown in Fig. 19, at near 100\% mullite compositions. This softening effect is much larger than that expected from a continuum model that envisions, in this case, zirconia as fluidlike but equiaxed inclusions. Therefore, some microscopic chemical or structrual effect on the grain boundary which facilitates diffusion or sliding is again implied.

\section{(3) Dynamic Grain Growth}

A perhaps unique mechanism predominant in superplasticity is dynamic grain growth. 85 Strong strain hardening is evident whenever grain growth occurs during superplastic deformation. This becomes significant in Y-TZP above $1450^{\circ} \mathrm{C}^{12,39.40}$ and in pure alumina above $1250^{\circ} \mathrm{C} .4^{41-43}$ Strong strain hardening was also observed in $12 \mathrm{Ce}$-TZP and $8 \mathrm{Y}$-CSZ at temperatures as low as $1200^{\circ} \mathrm{C},{ }^{20}$ The mechanistic origin of dynamic grain growth is probably related to grainboundary migration. ${ }^{85}$ These mechanisms are central features of superplasticity and are necessary for maintaining an equiaxed grain shape to large deformation strains. If grain-boundary migration is stochastic, which is usual in grainboundary sliding, ${ }^{86}$ and is not overdamped by solute drag or particle pinning, then it can lead to stochastic grain growth by chance elimination of certain grains in the process. ${ }^{87}$ Experimental data confirming this interpretation can be sought by writing the grain growth kinetics in the following form:

$\dot{d}=B d \dot{\varepsilon}$ 
where $\dot{d}$ is the rate of grain growth and $B$ is a proportionality constant that couples the strain rate through grain-boundary migration to the grain-growth rate. Thus, dynamic grain growth follows the equation

$d=d_{0} \exp (B \varepsilon)$

where $d_{0}$ is the initial grain size before deformation.

Experiments deliberately conducted in a temperatrue regime in which static grain growth is negligible (but dynamic grain growth is significant) have verified the above prediction. ${ }^{20}$ Figure 20 illustrates this behavior for several Ce-TZP ceramics tested in compression under various conditions. A linear correlation between In $\left(d / d_{0}\right)$ and $\varepsilon$ is evident, giving a value of $B$ of the order of unity. These data eventually deviate from the predicted linear relationship between In $d$ and $\varepsilon$. A review of the flow stress at the point of deviation suggests that it is probably high enough for yielding by slip to occur. When the latter becomes the dominant deformation mechanism, grain-boundary sliding, grain-boundary migration, and, hence, dynamic grain growth diminish in importance, and Eq. (4) is no longer valid because $\dot{\varepsilon}$ is no longer solely due to the boundary phenomena.

Note that dynamic grain growth never has been observed in coarse-grained (Cubic) zirconia ${ }^{71-74}$ and alumina ${ }^{54}$ that were deformed in the diffusional creep regime. This strongly suggests that, although diffusional creep also necessarily entails grain-boundary sliding and perhaps grain-boundary migration, the extent of these activities is not as significant as in superplasticity. Indeed, the sliding and migration could be qualitatively quite different in nature in that grain switching, ${ }^{41}$ grain rotation, 5 and grain-shape transformation, ${ }^{6}$ occurring in superplasticity, do not seem important for diffusional creep. Both considerations may dictate that deformation-stimulated stochastic grain growth is less likely in diffusional creep than that in superplasticity.

Dynamic grain growth introduces several complications to the stress-strain curves and the parameters in the consttutive equation (Eq. (1)). Using the relation between grain size and strain it is possible to recast the standard constitutive equation (Eq. (1)) into the following form:

In $\sigma=(B p / n) \varepsilon+\ln \left[\left(d_{0} p \dot{\varepsilon} / A\right)^{1 / n}\right]$

From Fig. 20 we find that $B$ approaches unity. If we let $p$ be 2 to 3 and $n$ be 1.5 to 2 , then $B p / n$ is between 1 and 2 . Using this form, stress-strain curves of Ce-TZP and pure alumina $\left(1250^{\circ} \mathrm{C}\right)$, which all suffer from severe dynamic grain growth but no static grain growth, are replotted in Fig. 21. Except for initial transients related to the elastic portions of the stressstrain curves, data in each branch appear to have a slope of 2, as expected from the above interpretation. For $8 Y-C S Z 20$ and alumina at higher temperatures, static grain growth is also prominent. This causes a higher strain hardening initially. At the later stage, as static grain growth decreases with increasing grain size, the terminal slope then approaches 2 again. These features are evident from their respective stress-strain curves, as shown in Fig. 21. The later leveling-off and the eventual drop of the flow stress in alumina $\left(1400^{\circ} \mathrm{C}\right)$ is due to cavitation (see Fig. 9(c)).

Temperature dependence of deforma-

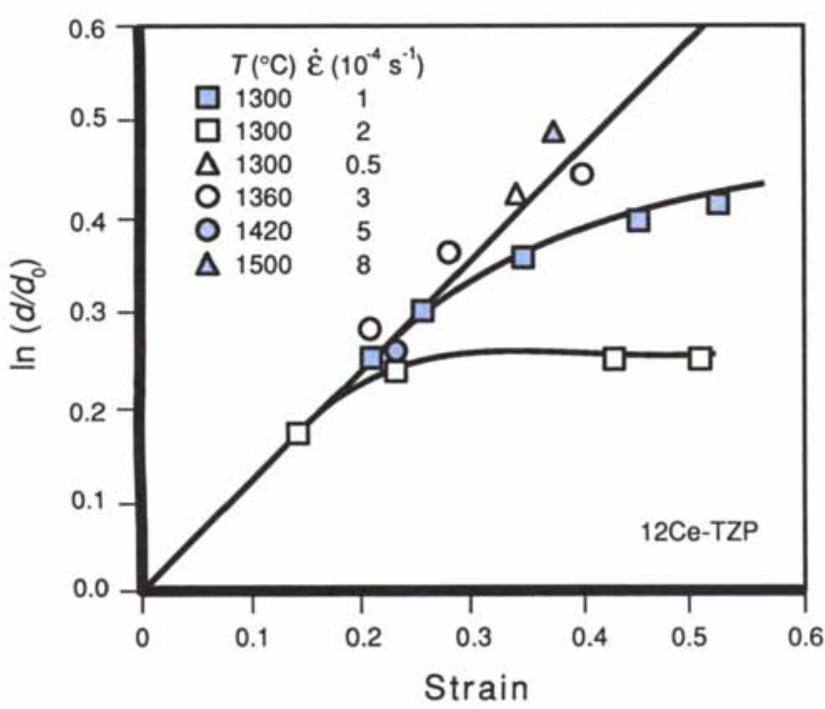

Fig. 20. Change in normalized grain size with strain of $12 \mathrm{Ce}-\mathrm{TZP}$, indicating dynamic grain growth. Data for various deformation conditions initially fall on a single line. Later deviation from the straight line is probably due to plastic yielding.

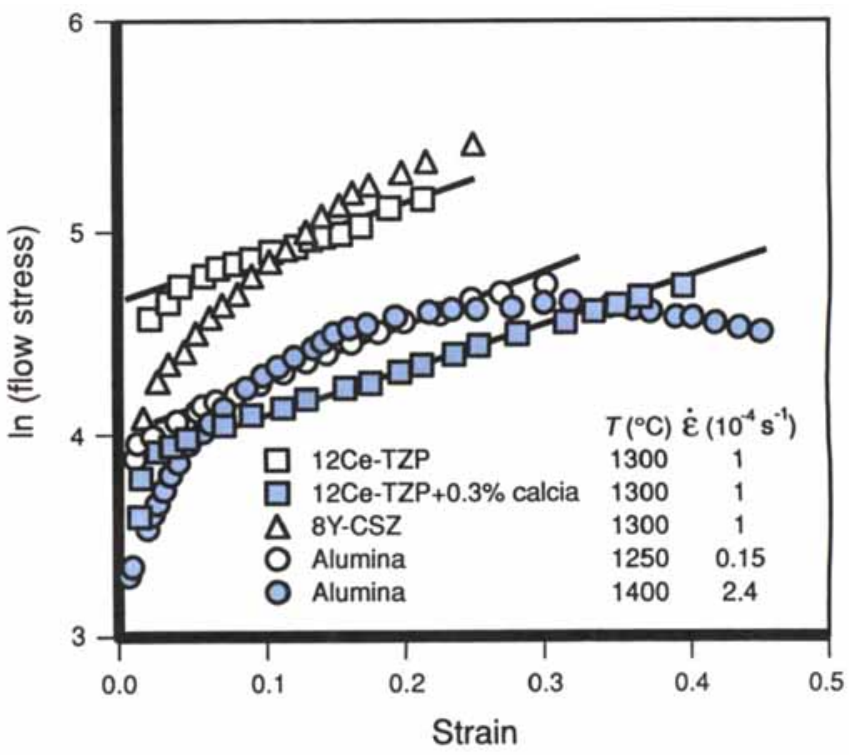

Fig. 21. Stress-strain curves of ceramics undergoing dynamic grain growth (Ce-TZP and alumina at $1250^{\circ} \mathrm{C}$ ) and others undergoing both dynamic and static grain growth. Note that stress is in logarithmic scale (see text). 


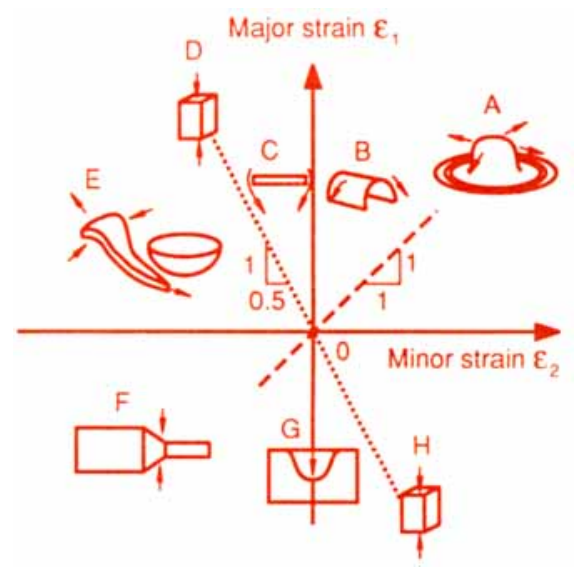

Fig. 22. Dominant strain states of various superplastic forming processes (see text for references)

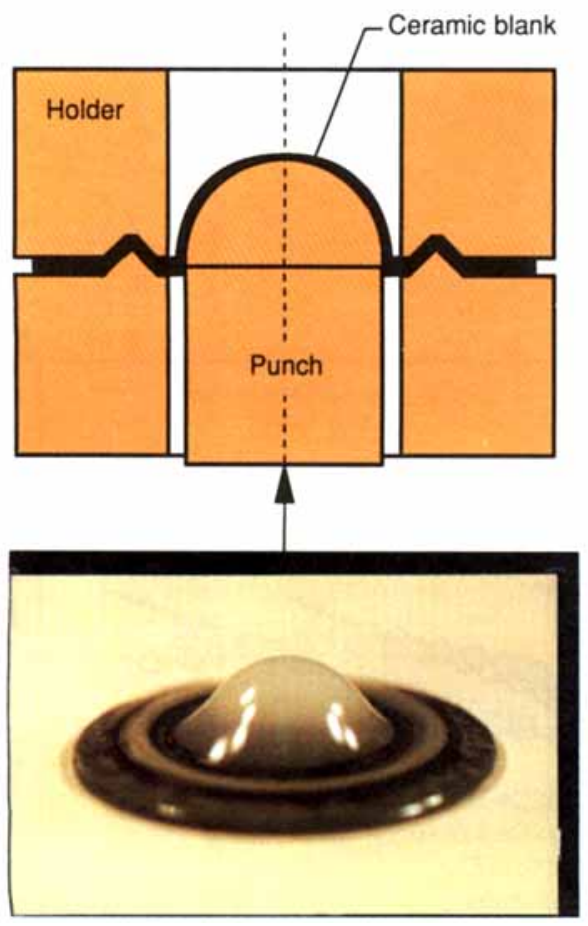

Fig. 23. (a) Schematic of punch-stretching test used to evaluate sheet formability in biaxial tension. (b) Punch-stretched 2Y-TZP with 0.3 mol\% copper(II) oxide. Note the excellent surface finish and the groove around the dome. Formed in air at $1150^{\circ} \mathrm{C}$ in $10 \mathrm{~min}$. tion may also be altered by dynamic grain growth. At higher temperatures, dynamic grain growth is faster because of a higher grain-boundary mobility. This causes increasing strain hardening and lowering of the apparent activation energy.

\section{(4) Summary}

In summary, deformation mechanisms controlling superplasticity in fine-grained ceramics are similar to diffusional creep and are dominated by grain-boundary diffusion. Very fine grain sizes and the frequent presence of a grain-boundary phase seem to cause interface reactions to become the rate-limiting step in many instances. The basic deformation characteristics of a material can be altered by the addition of a second phase, which causes hardening or softening, and by dynamic grain growth, which causes strain hardening. Semiempirical models are available to describe the various constitutive behaviors observed experimentally.

\section{Superplastic Forming}

\section{(1) Formability Test}

Many attempts have been made to form zirconia and other ceramics into shapes in the superplastic regime. The following forming methods have been attempted: uniaxial tension, uniaxial compression, bending, extrusion, inverse extrusion, and shell forming. These are shown schematically in Fig. 22, which indicates the dominant strain states of each method. Some methods involve tensile strain in one direction, such as uniaxial tension and bending ( $\mathrm{D}^{11}$ and $\mathrm{C}^{88}$ in Fig. 22). Others are dominated by compression, such as extrusion and inverse extrusion ( $F^{89}$ and $G^{89}$ in Fig. 22). In the shell-forming experiment ( $E$ in Fig. 22) of Mocellin et al. ${ }^{89}$ a balanced tensioncompression path was used. In bending of a wide plate ( $\mathrm{B}^{88}$ in Fig. 22) plane strain tension is encountered. Forming methods dominated by compression can also use powder preforms to achieve densification and shaping in one step, for example, in sinter forging and extrusion.

To evaluate formability of superplastic ceramics, a punch-stretching test ( $A$ in Fig. 22) has been developed. 90 This test was initially developed by metallurgists for evaluating sheet formability of metals at room temperature. ${ }^{3.91}$ Both mechanical and practical considerations have established that such a test is more severe and informative than the conventional tensile test for the above purpose, at least for sheet-forming processes. 3,91 In this test, an initially flat ceramic disk was punched at high temperature into a hat shape. The forming conditions-i.e., forming stress, strain rate, and temperature required to successfully complete the operationthen provide an indication of the formability of the ceramic. During forming, the disk was supported at the rim and was stretched over a hemispherical punch of a radius of $6.5 \mathrm{~mm}$. In some experiments, to ensure that there was no drawing-in of the material during subsequent stretching, a groove was first formed between matching dies, and the disk was clamped firmly, as shown in Fig. 23(a). The punch was advanced at a programmed displacement rate until a bulged dome of a height equal to the punch radius was formed. At this point, the surface area of the dome is approximately twice that of the base, corresponding to a biaxial engineering strain of $100 \%$.

Figure 1 shows a number of superplastically punch-stretched ceramics, with their approximate forming temperatures and times indicated. Generally, the required forming time increases with lower forming temperatures. This trend is shown by the three curves, which broadly outline the forming conditions for the three groups of ceramics. Among them, the zirconia ceramics with grain-boundary additives have the lowest forming temperature. Other oxide ceramics, especially ones with higher alumina content, required a higher forming temperature. Zirconia/mullite composites behave similarly, altough mullite has not yet been made superplastic. In the case of silicon nitride, $1500^{\circ} \mathrm{C}$ was necessary for successful punch stretching. Under the optimal forming conditions, 2Y-TZP with 0.3 mol\% copper(II) oxide additive can be formed at $1150^{\circ} \mathrm{C}$ in $10 \mathrm{~min} .90 \mathrm{~A}$ specimen so formed is shown in Fig. 23(b). Excellent surface finish is obtained in all cases, except alumina, by punch stretching.

The strain distribution of the punchstretched object has been measured using markers inscribed onto the surface of the disk before forming. ${ }^{90}$ This is shown in Fig. 24, in which strains are expressed as true strain. The slight depression around the pole is due to friction between the punch and the disk. A detailed analysis of the forming mechanics, which correctly predicts the strain distribution and the forming load-displacement curve measured experimentally, has been performed elsewhere. 19,90 To understand these results and for an order of magnitude estimation, we may approximate the punch-stretching test as pressure bulging from a circular disk to a hemispherical shell of the same radius. Because the total engineering strain is $100 \%$, the average strain rate is simply $\tau^{-1}$, where $\tau$ is the total forming time. The forming pressure $f$ on the shell must satisfy the yield criterion.

$f=2 Y t / R$

where $Y$ is the flow stress in uniaxial tension at the appropriate strain rate, $t$ is the thickness, and $R$ is the punch/disk radius. This bulge pressure is related to the punch load $P$ through 
$P=R^{2 f} \sin ^{2} \beta$

where $\beta$ is the half angle subtended by the edge of the punch contact to the center line. At the end of punch stretching, when the height of the dome is equal to the radius, $\beta$ is $90^{\circ}$ to $69^{\circ}$ for $t / R$ varying from 0 to 0.1 . Using Eqs. (7) and (8), forming pressure, flow stress, and average strain rate can be easily estimated. For example, a typical forming stress for doped zirconia was $20 \mathrm{MPa}$ at $1200^{\circ} \mathrm{C}$ and a strain rate of $3 \times 10^{4} \mathrm{~s}^{-1}$. For silicon nitride, a forming stress of $10 \mathrm{MPa}$ was recorded at $1560^{\circ} \mathrm{C}$ and a strain rate of $3 \times 10^{-4} \mathrm{~s}^{-1}$. For alumina, successful punch stretching was achieved at $1450^{\circ} \mathrm{C}$ with $25 \mathrm{MPa}$ and a strain rate of $3 \times 10^{-4} \mathrm{~s}^{-1}$.

Forming curves in terms of $P / t_{0} R$ and $h / R$, as a function of time, with $t_{0}$ being the initial thickness and $h$ the punch displacement, are shown in Figs. 25(a) and (b) for several materials formed under various loading/displacement conditions. During forming under a constant displacement rate, the average strain rate of the stretched material increases monotonically with time, reaching a maximum at the end. This causes a corresponding increase of forming stress. Using a variable displacement rate, which is faster initially but slower near the end, an approximate constant strain rate path can be achieved. This has the advantage of lowering the peak stress without necessarily increasing the total forming time so that failure probability is reduced. $90 \mathrm{~A}$ series of forming curves for a number of superplastic ceramics formed under this more favorable condition are shown in Fig. 25(b). Another alternative strategy used to lower the forming stress is to use a variable temperature ramp, which starts forming at a lower temperature and ends

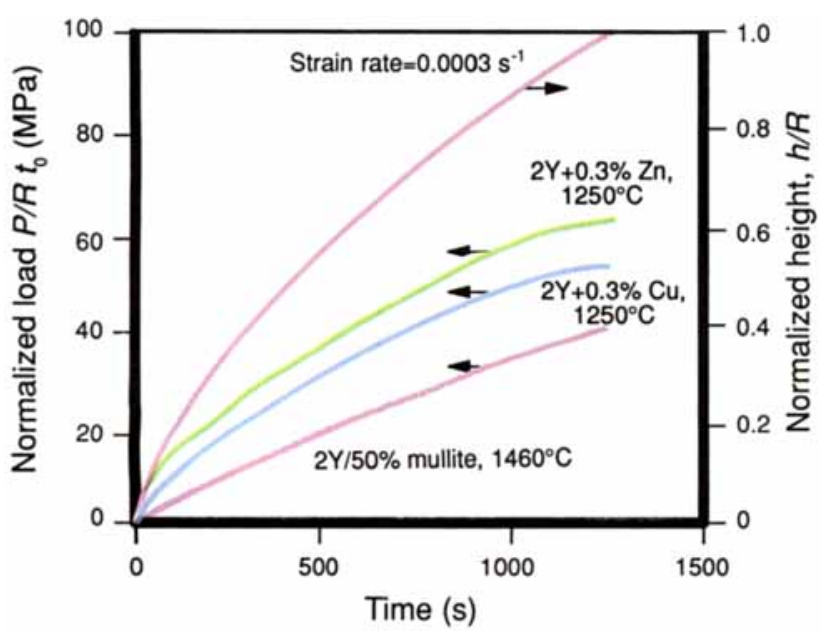

b

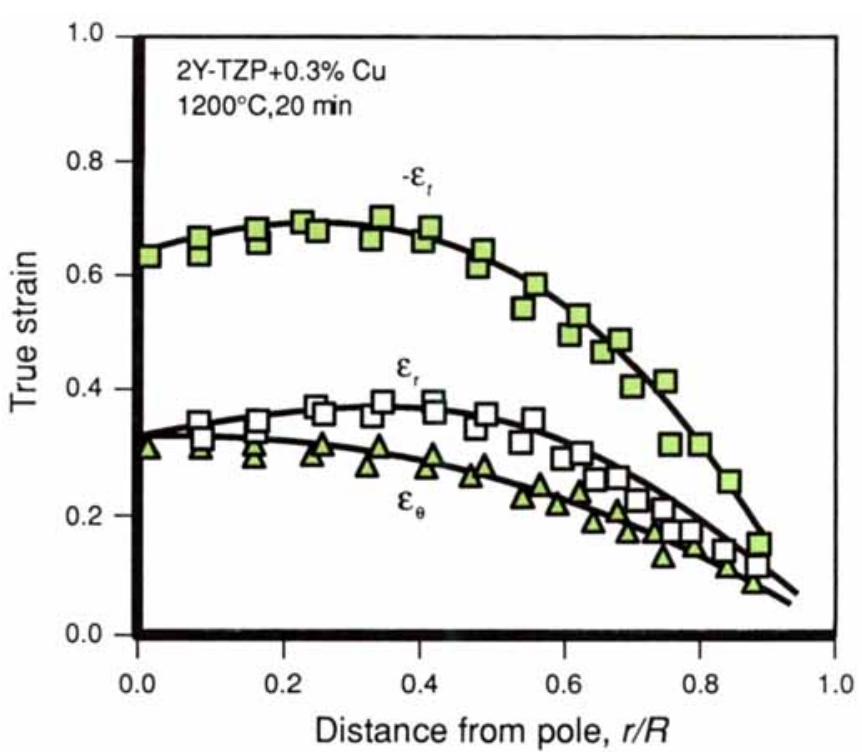

Fig. 24. Strain distribution on a punch-stretched $2 Y-T Z P$. Radial strain $\left(\varepsilon_{r}\right)$ and hoop strain $\left(\varepsilon_{\theta}\right)$ are measured by markers inscribed on the surface, and the thickness strain $\left(\varepsilon_{t}\right)$ is computed from $\varepsilon_{r}+\varepsilon_{\theta}+\varepsilon_{t}=0$.

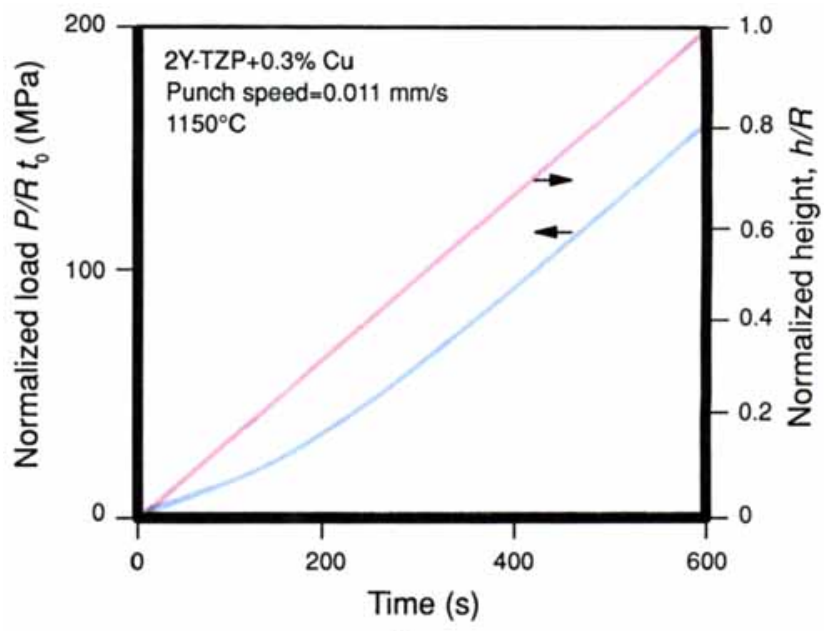

a

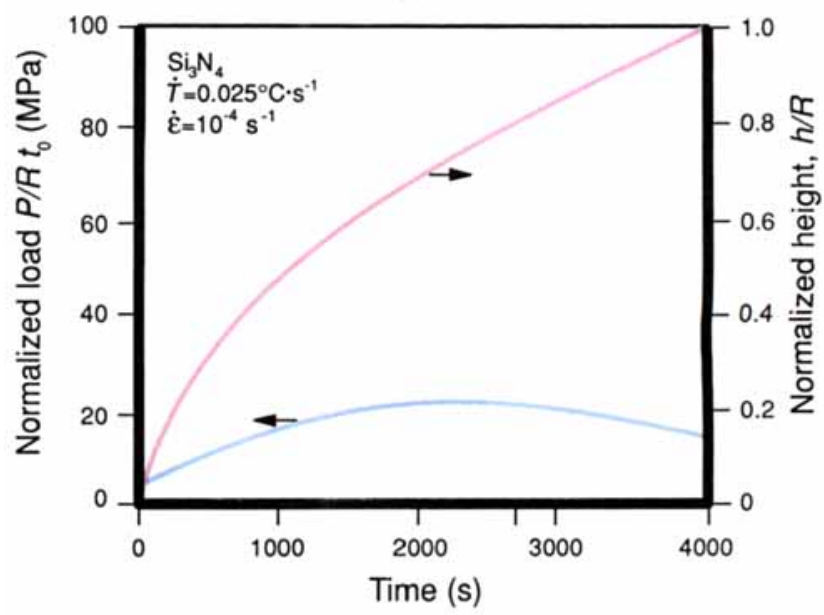

C

Fig. 25. (a) Forming load (normalized by punch radius $R$ and initial thickness $t_{0}$ ) and dome height (normalized by $R$ ) versus forming time in a punch-stretching test. Note the sharp increase of forming load with time under the constant punch speed condition. (b) Normalized forming load and normalized dome height versus time for 2Y-TZP with 0.3 mol\% zinc oxide, 2Y.TZP with 0.3 mol\% copper(II) oxide, and $2 Y$-TZP with 50 mol\% mullite. Forming schedule is programmed to achieve a constant strain rate. Note that the load increase is gradual and mild. (c) Normalized forming load and normalized dome height versus time for silicon nitride. A constant heating rate and a constant strain rate are used, starting at $1480^{\circ} \mathrm{C}$. 
at a higher temperature. An example of the latter, using a constant heating rate, is shown in Fig. 25(c). We have successfully formed silicon nitride and alumina using the latter schedule.

\section{(2) Fracture Control}

Formability is dictated by the strain to failure along the appropriate strain path representative of the forming route. Tensile ductilities of superplastic metals and alloys are known to correlate well with strain-rate sensitivity, $m$ (i.e., the reciprocal stress exponent). ${ }^{2}$ The higher the strain-rate sensitivity, the higher the tensile ductility. Such a correlation does not hold for superplastic ceramics, as shown in Fig. 26(a). To understand this, we recall that the physical basis of the ductility $-m$ correlation is in the stability against necking, which increases with $m$

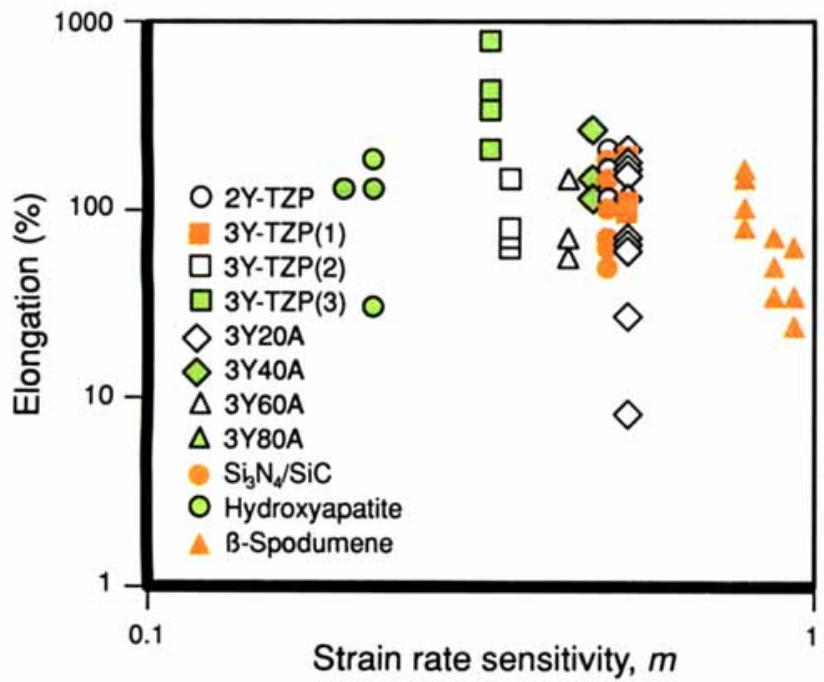

a

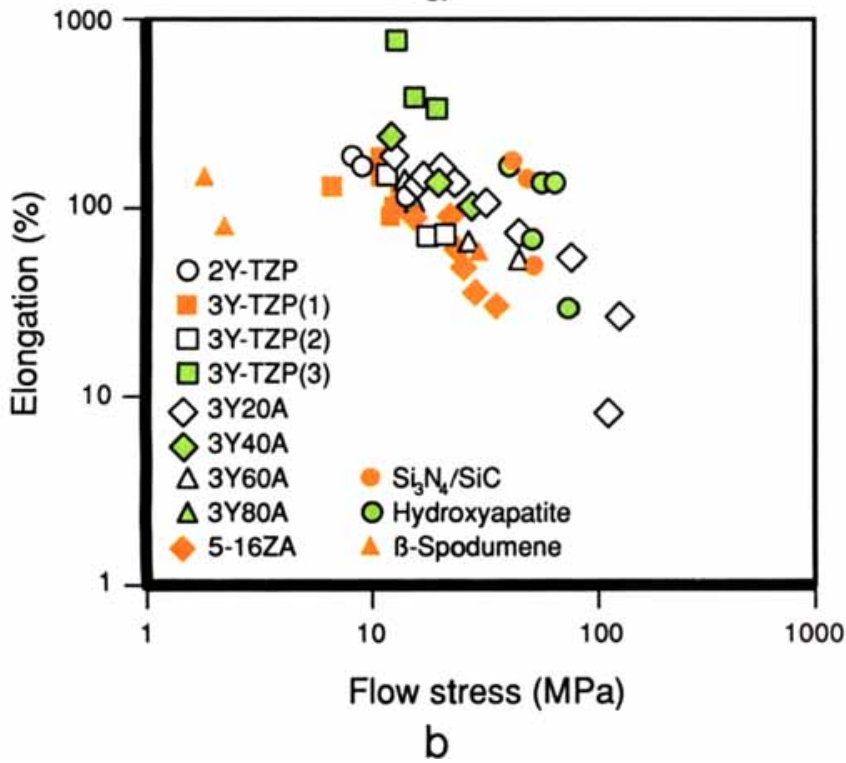

for a strain-rate-sensitivity material.3,8 The failure of this correlation, therefore, implies that, for superplastic ceramics, deformation stability is still essential, but is rarely the limiting factor for tensile ductility. Indeed, ductilities of superplastic ceramics should be much higher than those actually observed under most circumstances if necking were responsible for failure.

As a practical matter, grain-boundary decohesion always limits tensile ductility in superplastic ceramics. Although the exact mechanisms remain to be established, existing evidence supports the opinion that cavitation or grain-boundary cracking precedes fracture. Thus, cavitation resistance must figure prominently in evaluating formability. The central importance of grain-boundary cohesive strength, which controls the cavitation resistance, can thus be understood. On the other hand, for a given material, cavity and crack nucleation at grain boundaries under creep conditions is relatively insensitive to the temperature but extremely sensitive to the flow stress.86.92-94 The latter is, in turn, controlled by deformation temperature, strain rate, and strain hardening. This would suggest that a better correlation for formability may be one relating ductility to flow stress rather than to strain-rate sensitivity. The available data for tensile ductilities of all superplastic ceramics thus far reported, plotted in Fig. 26(b), seem to support such a proposition in that a reasonably good correlation exists between increasing tensile elongation and decreasing flow stress for each group of materials. Indeed, after normalizing the flow stress by the reference stress that causes failure at $100 \%$ elongation for

Fig. 26. (a) Lack of correlation between tensile elongation and strain rate sensitivity $m$. References are 12 for $2 Y$-TZP; 40 for $3 Y-T Z P(1) ; 28$ for $3 Y$-TZP(2); 26 and 101 for $3 Y$-TZP(3); 40 for 3Y20A, 3Y40A, 3Y60A, and 3Y80A; 22 for silicon nitride/silicon carbide; 14 for hydroxyapatite; and 102 for $\beta$-spodumene. An example of the notation for the composites is that 3Y20A means $3 Y$-TZP with 20 wto aiumina. (b) Close correlation between tensile elongation and flow stress (5-16ZA means 5 to 16 vol\% of $3 Y$-TZP in alumina matrix) (data from Ref. 48; otherwise the references and notations are the same as for Fig. 26(a)). (c) Close correlation between tensile elongation and normalized flow stress. The flow stress of each material is normalized by $0100 \%$, which is the flow stress in Fig. 26(b) at an elongation of $100 \%$ for each material. 
each group of ceramics, a clear trend common to all superplastic ceramics emerges, as shown in Fig. 26(c). This may be contrasted with the common observation, for superplastic metals and alloys, of a ductility maximum at an intermediate flow stress, which coincides with the maximum of strain-rate sensitivity. 2.3 Because the strain rate sensitivity is largely independent of elongation in Fig. 26(a), the strong correlation between elongation and flow stress in Figs. 26(b) and (c) must be regarded as a manifestation of the stress-controlled failure process unique to ceramics.

In the case of alumina/3Y-TZP composites, Wakai et al. have previously noted that the average alumina grain size correlates poorly with ductility, but that the size of the largest alumina grains in the composites correlates well. 48 This observation seems particularly explicable for alumina, which is prone to anisotropic, abnormal grain growth. The few large grains in an otherwise fine-grained matrix have a relatively minor influence on the average flow stress (see Eq. (3)) but cause considerable stress concentrations because of their poorer diffusional accommodation as a result of the longer diffusion distances in their vicinity. Therefore, these grains can cause enhanced cavitation, which is detrimental to tensile ductility. Other stress-concentrating heterogeneities will have a similar effect. Likewise, the deleterious effect of strain hardening on ceramic superplasticity is understandable, despite its supposediy beneficial influence on deformation stability. ${ }^{8}$ Lowering the flow stress and increasing the grain-boundary strength thus provide the most effective methods for improving superplastic formability.

For ceramics, the superplastic punchstretching test described above is a much more severe formability test than the uniaxial tension test favored by most investigators to characterize superplasticity. Generally speaking, fractures in ceramics are initiated at preexisting flaws introduced by preparation steps such as powder packing, sintering, and machining. In uniaxial tension, only preexisting cracks perpendicular to the stress axis may cause fracture. In biaxial stretching, cracks of all orientations are being stressed and may be fatal. Although the flaw tolerance at the forming temperature has been dramatically improved in superplastic ceramics, most of our failures that occurred were brittle in nature, especially at higher forming rates. ${ }^{19}$ This also supports the conclusion that grain-boundary decohesion rather than necking is the failure-controlling event. Because variously oriented cracks are stressed and failure is brittle in nature, biaxial stretching experiments are much needed demonstration tests which should be routinely performed for superplastic ceramics to ensure their suitability for practical sheetforming in applications.
For reliable, flaw-free forming, the current practice in the superplastic metal industry is to use pressure forming in a configuration where the differential pressure effects shape deformation while the mean pressure suppresses cavitation. $7,9,10$ in theory, a pressure on the order of the flow stress should be sufficient for suppression of cavity growth, 95,96 thus avoiding failure. Such an approach has been found to be successful for glassceramics, which can be stretched to $100 \%$ once cavitation is suppressed. ${ }^{97}$ Because of the propensity for cavitation in many ceramics and the paramount importance of reliability to ceramic applications, we predict that a similar practice will eventually be adoped if superplastic sheet forming of structural ceramics should become a commercial endeavor.

\section{v. Conclusions}

Since the discovery of ceramic superplasticity in 1986, considerable progress in zirconia and other superplastic ceramics has been achieved. In this paper, we have attempted to provide instructive examples from this experience. Through these examples, we have emphasized the importance of structural and processing controls in achieving a superior microstructure and formability, the central role of static and dynamic characteristics of grain boundaries and phase boundaries, and the major differences between superplastic ceramics and their counterparts in metals and alloys. With powders of ever-improving sinterability and finer particle size becoming increasingly available, a lower sintering temperature, which is synonymous to a more uniform and finer microstructure, has been achieved for several major structural ceramics during the last few years. Complementary research on physical ceramics has further elucidated some of the basic principles of microchemical and microstructural control and directed the way of alloy development for better deformability and ductility. These interrelated materials con. siderations, previously outlined in Fig. 2, have now been addressed in some detail in this paper. The key issues discovered here are summarized in a block diagram in Fig. 27 for various structure-property-processing relationships. Although the implementation and specifics may vary from ceramic to ceramic, and further basic and applied research is still desirable, it is our hope that Fig. 27 will nevertheless provide a sketchy but useful "road map" to guide future superplastic ceramic development.

Looking forward, it is our opinion that most, if not all, ceramics can be rendered superplastic at reasonable forming temperatures and forming times no higher or longer than those currently used in com. mercial practice for ceramic sintering. We believe that our optimism is well based, judging from the experience in zirconia, alumina, silicon nitride, and their compos- 


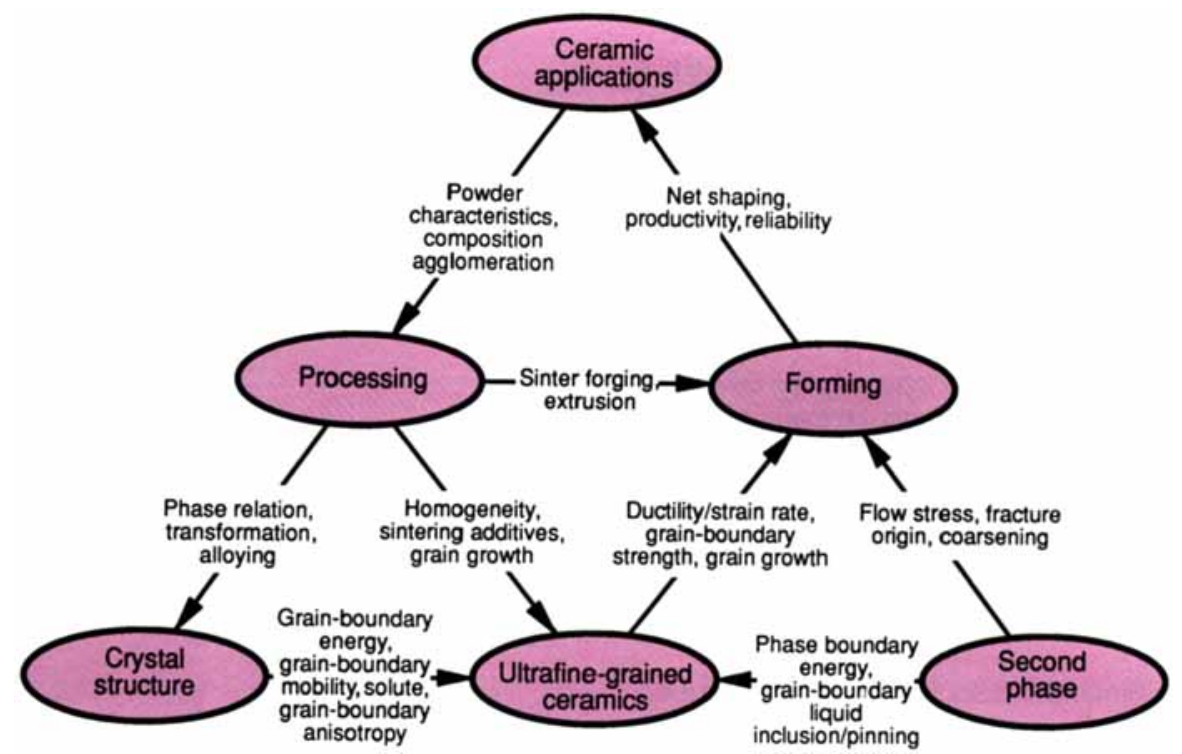

Fig. 27. Major issues in the structure-property-processing relationships in superplastic ceramics for structural applications.
BE. W. Hart, "Theory of the Tensile Test," Acta Metall., 15 [2] 351-55 (1967).

9 N. E. Paton and C. H. Hamilton (editors), Superplastic Forming of Structural Alloys; pp. 257-71. The Metallurgical Society of AIME, Warrendale, PA, 1982.

10M. Doyama, S. S. Sōmiya, R. P. H. Chang, M. Kobayashi, and F. Wakai, Superplasticity, MRS Conference Proceedings, International Meeting on Ad. vanced Materials, Vol. 7. Materials Research Society, Pittsburgh, PA, 1989

${ }^{11} \mathrm{~F}$. Wakai, S. Sakaguchi, and Y. Matsuno, "Superplasticity of Ytria-Stabilized Tetragonal $\mathrm{ZrO}_{2}$ Polycrystals," Adv. Ceram. Mater., 1 [3] 259-63 (1986).

12F. Wakai, $Y$, Kodama, and T. Nagano, "Superplasticity of $\mathrm{ZrO}_{2}$ Polycrystals," Jpn. J. Appl. Phys., 28. 69-79 (1989)

${ }^{13} \mathrm{~L}$. A. Xue and $\mathrm{I}-\mathrm{W}$. Chen; unpublished research presented at the 92nd Annual Meeting of the American Ceramic Society, Dallas, TX, April 22-26, 1990 (Paper No. 5-JV-90).

14F. Wakai, Y. Kodama, S. Sakaguchi, and T. Nonami, "Superplasticity of Hot Isostatically Pressed Hydroxyapatite," J. Am. Ceram. Soc., 73, 457-60 (1990)

15F. Wakai and H. Kato, "Superplasticity of TZP $/ \mathrm{Al}_{2} \mathrm{O}_{3}$ Composite," Adv. Ceram. Mater., 3 [1] 71-76 (1988).

16F. Wakai, Y. Kodama, S. Sakaguchi, N. Murayama, H. Kato, and T. Nagano, "Superplastic Deformation of $\mathrm{ZrO}_{2} / \mathrm{Al}_{2} \mathrm{O}_{3}$ Duplex Composites"; pp 259-66 in Superplasticity, MRS Conference Proceedings, International Meeting on Advanced Materials, Vol. 7. Edited by M. Doyama, S. S. Sōmiya, R. P. H. Chang, M. Kobayashi, and F. Wakai. Materials Research Society, Pittsburgh, PA, 1989.

${ }^{17} \mathrm{C}$. K. Yoon and I-W. Chen, "Superplastic Flow of Two-Phase Ceramics Containing Rigid inclusions-Zirconia/Mullite Composites," J. Am. Ceram Soc, 73 [6] 1555-65 (1990)

${ }^{18} \mathrm{C}$. K. Yoon, "Superplastic Flow of Mullite/2Y-TZP Composites"; Ph.D. Thesis. Department of Materials Science and Engineering, University of Michigan Ann Arbor, Ml, 1990.

19X. Wu, "Deformation Processing of Ceramics" Ph.D. Thesis. Department of Materials Science and Engineering, University of Michigan, Ann Arbor, MI 1990.

20I-W. Chen and S. L. Hwang; unpublished research presented at the 91st Annual Meeting of the American Ceramic Society, Indianapolis, IN, Apri 23-27, 1989 (Basic Science Division, Paper No 120-B-89); and 92nd Annual Meeting of the American Ceramic Society, Dallas, TX, April 22-26, 1990 (Basic Science Division, Paper Nos. 25-B-90 and 26-B-90)

21F. Wakai, Y. Kodama, S. Sakaguchi, N. Murayama, K. izaki, and K. Nihara, "A. Superpiastic Covalent Crystal Composite," Nature (London), 344 421-23 (1990)

${ }^{22}$ F. Wakai, Y. Kodama, S. Sakaguchi, N. Murayama, K. Izaki, and K. Nihara, "Superplasticity of NonOxide Ceramics"; to be published in MRS Symposium Proceedings on Superplasticity in Metals, Cer amics, and Intermetallics. Edited by M. I. Mayo, J Wadsworth, A. K. Mukherjee, and M. Kobayashi Materials Research Society, Pittsburgh, PA, 1990 23R. J. Brook, "Controlled Grain Growth": pp 331-64 in Treatise on Materials Science and Technology, Vol. 9 . Edited by F. F. Wang. Academic Press, New York, 1976

${ }^{24} \mathrm{C}-\mathrm{M}$. J. Hwang and I-W. Chen, "Effect of a Liquid Phase on Superplasticity of 2-mol\% $\%-\mathrm{Y}_{2} \mathrm{O}_{3}$ Stabilized Tetragonal Zirconia Polycrystals," J. Am. Ceram. Soc., 73 [6] 1626-32 (1990).

25 T. Hermansson, K. P. D. Lagerlof, and G. L. Dunlop, Superplasticity and Superplastic Forming; $p$. 631. Edited by C. H. Hamilton and N. E. Paton. The Metallurgical Society of AIME, Warrendale, PA, 1988 26T. G. Nieh, C. M. McNally, and J. Wadsworth, "Superplastic Properties of a Fine-Grained Yttria- 
Stablized Tetragonal Polycrystal of Zirconia," Scripta Metall., 22, 1297-300 (1988)

27R. Ducios, J. Crampon, and B. Amana, "Structural and Topological Study of Superplasticity in Zirconia Polycrystals," Acta Metall, 37 [3] 877-83 (1989).

${ }^{28} \mathrm{C}$. Carry, "High Ductilities, Superplastic Behavior, and Associated Mechanisms in Fine-Grained Ceramics"; in Superplasticity, MRS Conference Proceedings, International Meeting on Advanced Materials, Vol. 7. Edited by M. Doyama, S. S. Sōmiya, R. P. H. Chang, M. Kobayashi, and F. Wakai. Materials Research Society, Pittsburgh, PA, 1989.

29T. K. Gupta, J. H. Bechtold, R. C. Kuznicki, L. H. Cadoff, and B. R. Rossing, "Stabilization of Tetragonal Phase in Polycrystalline Zirconia," J. Mater. Sci., 12, 2421-26 (1977).

30T. K. Gupta, "Sintering of Tetragonal Zirconia and Its Characteristics, "Sci. Sintering, 10 [3] 205-16 (1978).

31T. K. Gupta, F. F. Lange, and J. H. Bechtold "Effect of Stress-Induced Phase Transformation on the Properties of Polycrystalline Zirconia Containing Metastable Tetragonal Phase," J. Mater. Sci, 13. 1464-70 (1978)

321-W. Chen, Y. H. Chiao, and K. Tsuzaki, "Statistics of Martensitic Nucleation," Acta Metall, 33 [10] 1847-59 (1985)

33K. Tsukuma, Y. Kubota, and T. Tsukidate, "Thermal and Mechanical Properties of $\mathrm{Y}_{2} \mathrm{O}_{3}$-Stabilized Tetragonal Zirconia Polycrystals "; pp. 382-90 in Advances in Ceramics, Vol. 12, Science and Technology of Zirconia II. Edited by N. Claussen, M. Rühle, and A. H. Heuer. American Ceramic Society, Colum. bus, $\mathrm{OH}, 1983$

${ }_{34} \mathrm{~F}$. F. Lange, "Transformation-Toughened $\mathrm{ZrO}_{2}$ Correlations between Grain-Size Control and Composition in the $\mathrm{ZrO}_{2}-\mathrm{Y}_{2} \mathrm{O}_{3}$ System," J. Am. Ceram. Soc., 69 [3] 240-42 (1986)

$35 \mid$. G. Lee and I-W. Chen, "Sintering and Grain Growth in Tetragonal and Cubic Zirconia"; $p p$ 340-45 in Sintering ' 87 . Proceedings of the 4th International Symposium on Science and Technology of Sintering, Vol. 2, Nov. 4-7, 1987, Tokyo, Japan. Edited by S. S. Sōmiya, M. Shimada, M. Yoshimura and R. Watanabe. Elsevier Applied Science, London U.K., 1988

36S. L. Hwang and I-W. Chen, "Grain-Size Control of Tetragonal Zirconia Polycrystals Using the Space Charge Concept"; to be published in J. Am. Ceram. Soc., (1990).

37Y. Oishi, K. Ando, and Y. Sakka "Lattice and Grain-Boundary Diffusion Coefficients of Cations in Stabilized Zirconias"; pp. 208-19 in Advances in Ceramics, Vol. 7, Characterization of Grain Bound aries. Edited by M. F. Yan and A. H. Heuer. American Ceramic Society, Columbus, OH, 1983.

38W. D. Kingery, H. K. Bowen, and D. R. Uhlmann Introduction to Ceramics; p. 240. Wiley, New York 1976.

39F. Wakai, S. Sakaguchi, and H. Kato "Compressive Deformation Properties and Microstructures in the Superplastic Y-TZP," J. Ceram. SoC. Jpn., 94 [8] $721-25$ (1986).

40F. Wakai, 'Superplasticity of Zirconia-Toughened Ceramics"; Ph.D. Thesis. Kyoto University, Kyoto. Japan, 1988

${ }_{41} \mathrm{~J}$. D. Fridez, C. Carry, and A. Mocellin, "Effects of Temperature and Stress on Grain-Boundary Behavior in Fine-Grained Alumina'; pp. 720-40 in Ad vances in Ceramics, Vol. 10, Structure and Properties of $\mathrm{MgO}$ and $\mathrm{Al}_{2} \mathrm{O}_{3}$ Ceramics. Edited by W. D. Kingery. American Ceramic Society, Columbus, $\mathrm{OH}$, 1984

${ }^{42}$ C. Carry and A. Mocellin, "Structural Superplasticity in Single-Phase Crystalline Ceramics, " Ceram. Int., 13, 89-98 (1987).

$43 \mathrm{~K}$. R. Venkatachari and R. Raj, "Superplastic Flow in Fine-Grained Alumina," J. Am. Ceram. Soc., 69 [2] 135-38 (1986)
44J. W. Cahn, "The Impurity Drag Effect in GrainBoundary Motion," Acta Metall, 10 [9] 789-98 (1962)

45I-W. Chen and C-M. J. Hwang; unpublished research.

46M. Rühle, N. Claussen, and A. H. Heuer, "Microstructural Studies of $\mathrm{Y}_{2} \mathrm{O}_{3}$-Containing Tetragonal $\mathrm{ZrO}_{2}$ Particles"; pp. 352-70 in Advances in Ceramics, Vol. 12, Science and Technology of Zirconia II. Edited by N. Claussen, M. Rühle, and A. H. Heuer. American Ceramic Society, Columbus, $\mathrm{OH}, 1984$

47E. M. Levin, C. R. Robbins, and H. F. McMur die, Phase Diagrams for Ceramists, 1969. Edited by M. K. Reser. American Ceramic Society, Columbus, $\mathrm{OH}$; Figs. 2145 and 2146

48T. Kuroishi, K. Uno, and F. Wakai, "Characterization of Superplastic $\mathrm{ZrO}_{2}$-Toughened $\mathrm{Al}_{2} \mathrm{O}_{3}$ Prepared by Slip Casting"'; pp, 267-74 in Superplasticity, MRS Conference Proceedings, International Meeting on Advanced Materials, Vol. 7. Edit ed by M. Doyama, S. S. Sömiya, R. P. H. Chang, M Kobayashi, and F. Wakai. Materials Research Society, Pittsburgh, PA, 1989

49P. Gruffel, C. Carry, and A. Mocellin, "Effect of Testing Conditions and Doping on Superplastic Creep of Alumina," Rev. Phys. Appl., 23 [4] 716 (1988)

50P. Gruffel, C. Carry, and A. Mocellin, "Effect of Testing Conditions and Doping on Superplastic Creep of Alumina," Sci. Ceram., 14, 587-92 (1988).

siW. R. Cannon, "High Ductility in Alumina Containing Compensating Additives"; pp. 741-49 in Advances in Ceramics, Vol. 10, Structure and Properties of $\mathrm{MgO}$ and $\mathrm{Al}_{2} \mathrm{O}_{3}$ Ceramics. Edited by W. D. Kingery. American Ceramic Society, Columbus, $\mathrm{OH}$ 1984.

52C. Carry and A. Mocellin, "High Ductilities in Fine-Grained Ceramic"; Ch. 16, pp. 16.1-16.19 in Superplasticity. Edited by B. Baudelet and M. Suery Centre National de la Recherche Scientifique, Paris France, 1985

${ }^{53}$ T-S. Yeh and M. D. Sacks, "Low-Temperature Sintering of Aluminum Oxide, " J. Am. Ceram. Soc. 71 [10] 841-44 (1988)

${ }_{54}$ R. M. Cannon, W. H. Rhodes, and A. H. Heuer "Plastic Deformation of Fine-Grained Alumina $\left(\mathrm{Al}_{2} \mathrm{O}_{3}\right)$ : I, Interface-Controlled Diffusional Creep," J. Am. Ceram. Soc. 63 [1-2] 48-53 (1980).

55W. H. Rhodes, "Agglomerate and Particle-Size Effects on Sintering Yttria-Stabilized Zirconia," J. Am. Ceram. Soc., 64 [1] 19-22 (1981).

56F. F. Lange, "Powder Processing Science and Technology for Increased Reliability," J. Am. Ceram. Soc., 72 [1] 3-15 (1989).

57W. A. Kaysser, M. Sprissler, C. A. Handwerker and J. Blendell, "Effect of a Liquid Phase on the Morphology of Grain Growth in Alumina," J. Am. Ceram. Soc., 70 [5] 339-43 (1987).

${ }^{58} \mathrm{C}-$ W. Li and W. D. Kingery, "Solute Segregation at Grain Boundaries in Polycrystalline $\mathrm{Al}_{2} \mathrm{O}_{3}$ "; $\mathrm{pp}$. 368-78 in Advances in Ceramics, Vol. 10, Structure and Properties of $\mathrm{MgO}$ and $\mathrm{Al}_{2} \mathrm{O}_{3}$ Ceramics. Edited by W. D. Kingery. American Ceramic Society, Columbus, $\mathrm{OH}, 1984$

59S. K. Roy and R. L. Coble, "Solubilities of Magnesia, Titania, and Magnesium Titanate in Aluminum Oxide," J. Am. Ceram. Soc., 51 [1] 1-6 (1968)

60S. Hampshire, H. K. Park, D. P. Thompson, and K. H. Jack, " $\alpha$ '-sialon Ceramics," Nature (London), 274 [5674] 880-82 (1978)

61L. J. Gauckler, H. L. Lukas, and T. Y. Tien, "Crystal Chemistry of $\beta-\mathrm{Si}_{3} \mathrm{~N}_{4}$ Solid Solutions Containing Metal Oxides," Mater. Res. Bull., 11 [5] 503-12 (1976).

62L. J. Gauckler, J. Weiss, T. Y. Tien, and G. Pet zow, "Insolubility of $\mathrm{Mg}$ in $\beta-\mathrm{Si}_{3} \mathrm{~N}_{4}$ in the System AlMg-Si-O-N," J. Am. Ceram. Soc., 61 [9-10] 397-98 (1978).

${ }^{63} \mathrm{C} . \mathrm{M}$. Hwang, T. $Y$. Tien and $\mathrm{H}-\mathrm{W}$. Chen, "Anisotropic Grain Growth in Final Stage Sintering 
of Silicon Nitride Ceramics'; pp. 1034-39 in Sintering ' 87 . Proceedings of 4 th International Symposium on Science and Technology of Sintering, Vol. 2 , Nov. 4-7, 1987, Tokyo, Japan. Edited by S. S. Sōmiya, M. Shimada, M. Yoshimura, and R. Watanabe. Elsevier Applied Science, London, U.K., 1988

${ }^{64} \mathrm{C}$. M. Hwang and T. Y. Tien, "Densification and Phase Transformation During Sintering of Silicon Nitride Ceramics"; pp. 1028-33 in Sintering '87, Proceedings of 4 th International Symposium on Science and Technology of Sintering, Vol. 2, Nov. 4-7, 1987, Tokyo, Japan. Edited by S. S. Sömiya, M. Shimada, M. Yoshimura, and R. Watanabe. Elsevier Applied Science, London, U.K., 1988.

${ }^{65} \mathrm{~F}$. Wakai, "A Review of Superplasticity in $\mathrm{ZrO}_{2}$-Toughened Ceramics," $\mathrm{Br}$. Ceram. Trans. J., 88 [6] 205-208 (1989)

${ }^{66} \mathrm{C}$. Zener; private communication to the author. See C. S. Smith, "Grains, Phases, and Interfaces: An Interpretation of Microstructure," Trans. AME, 175 , 15-51 (1948).

67P. Hellman and M. Hillert, "On the Effect of Second-Phase Particles on Grain Growth," Scand. J. Metall., 4 [5] 211-19 (1975)

68I. N. Braisford and P. Wynblatt, "The Dependence of Ostwald Ripening Kinetics on Particle Volume Fraction," Acta Metall. 27 [3] 489-97 (1979)

${ }^{69} \mathrm{~A}$. Ball and M. M. Hutchinson, "Superplasticity in the Aluminum-Zinc Eutectoid, " Met. Sci. J., 3 [1] $1-7$ (1969)

70A. K. Mukherjee, "The Rate-Controlling Mechanism in Superplasticity, "Mater. Sci Eng., 8 [2] 83-89 (1971)

71P. E. Evans, "Creep in Yttria- and Scadia Stabilized Zirconia," J. Am. Ceram. Soc, 53 [7] 365-69 (1970)

72L. L. Fehrenbecher, F. P. Bailey, and N. A. McKinnon, "Compressive Creep of Yttria-RareEarth-Stabilized Zirconia Storage Heater Refractories," SAMPE Q, 2 [4] 18-30 (1971).

${ }^{73} \mathrm{M}$. S. Seltzer and P. K. Talty, "High-Temperature Creep of $\mathrm{Y}_{2} \mathrm{O}_{3}$-Stabilized $\mathrm{ZrO}_{2}$," J. Am. Ceram. Soc. 58 [3-4] 124-30 (1975)

74D. Dimos and D. C. Kohlstedt. "Diffusional Creep and Kinetic Demixing in Yttria-Stabilized Zirconia," J. Am. Ceram. Soc., 70 [8] 531-36 (1987).

${ }^{75} \mathrm{~F}$. Wakai and T. Nagona, "The Role of InterfaceControlled Diffusion Creep on Superplasticity of Yttria-Stabilized Tetragonal $\mathrm{ZrO}_{2}$ Polycrystals," J Mater. Sci. Lett, , 7, 607-609 (1988).

${ }^{76} \mathrm{~A}$. Dominguez-Rodriguez, K. P. D. Lagerlof, and A. H. Hever, "Plastic Deformation and Solid-Solution Hardening of $\mathrm{Y}_{2} \mathrm{O}_{3}$-Stabilized $\mathrm{ZrO}_{2}$ " $J$. Am. Ceram Soc., 69 [3] 281-84 (1986).

77S. Takeuchi and A. S. Argon, "Review-SteadyState Creep of Single-Phase Crystalline Matter at High Temperature," U. Mater. Sci. 11, 1542-66 (1976).

${ }^{78} \mathrm{E}$. Arzt, M. F. Ashby, and R. A. Verrall, "InterfaceControlled Diffusional Creep." Acta Metall, 31 [12] 1977-89 (1983)

${ }^{79} \mathrm{~B}$. Burton, "Interface-Reacton-Controlled Diffusional Creep, A Consideration of Grain-Boundary Dislocation Climb Sources." Mater. Sci. Eng, 10 [1] 9-14 (1972)

${ }^{80} \mathrm{~J}$. W. Cahn, "Theory of Crystal Growth and Interface Motion in Crystalline Materials, " Acta Metall., 8 [8] 554-62 (1960)

${ }^{81}$ R. Raj and C. K. Chyung, "Solution-Precipitation Creep in Glass Ceramics," Acta Metall., 29 [1] 159-66 (1981).

${ }^{82} \mathrm{~F}$. Wakai, T. Iga, and T. Nagano, "Effect of Dis persion of $\mathrm{ZrO}_{2}$ Particles on Creep of Fine-Grained $\mathrm{Al}_{2} \mathrm{O}_{3}$," J. Ceram. Soc. Jpn., 96 [12] 1206-209 (1988)
83I-W. Chen and A. S. Argon, "Steady-State PowerLaw Creep in Heterogeneous Alloys with Coarse Microstructures," Acta Metall, 27, 785-91 (1979)

84P. C. Dokko, J. A. Pask, and K. S. Mazdiyasni. "High-Temperature Mechanical Properties of Mullite Under Compression," J. Am. Ceram. Soc., 60 [3-4] 150-55 (1977)

850. S. Wilkinson, "Grain-Size Effects in Superplasticity"; Ch. 6, pp. 6.1-6.6 in Superplasticity. Edited by B. Baudelet and M. Suery. Centre National de la Recherche Scientifique, Paris, France, 1985.

86|-W. Chen and A. S. Argon, "Creep Cavitation in 304 Stainless Steel," Acta Metall., 29, 1321-33 (1981).

87/-W. Chen, "A Stochastic Theory of Grain Growth," Acta Metall., 35, 1723-33 (1987)

${ }^{88} \mathrm{~F}$. Wakai, S. Sakaguchi, K. Kanayama H. Kato, and $H$. Onishi, "Hot Work of Yttria-Stabilized Tetragonal $\mathrm{ZrO}_{2}$ Polycrystals'"; pp. 315-22 in Ceramic Materials and Components for Engines. Edited by $W$. Bunk and $H$. Hausner. Deutsch Keramische Gesellschaft, FRG, 1986.

${ }^{89} \mathrm{C}$. Carry and A. Mocellin, "Examples of Superplastic-Forming Fine-Grained $\mathrm{Al}_{2} \mathrm{O}_{3}$ and $\mathrm{ZrO}_{2}$ Ceramics'; High Tech Ceramics, Materials Science Monograph 38A. Edited by P. Vincenzini. Elsevier Applied Science, Amsterdam, Netherlands, 1987.

$90 X$. Wu and I-W. Chen, "Superplastic Bulging of Fine-Grained Zirconia," J. Am. Ceram. Soc., 73 [3] 746-49 (1990)

91S. S. Hecker and A. K. Ghosh, "The Forming of Sheet Metal," Sci. Am., [Nov.] 100-109 (1976).

${ }^{92}$ A. S. Argon, I-W. Chen, and C. W. Lau, "Intergranular Cavitation in Creep"; pp. 46-85 in CreepFatigue-Environment Interactions. Edited by R. M. Pelloux and N. S. Stoloff. The Metallurgical Society of AIME, Warrendale, PA, 1980

${ }^{93}$ R. Raj and M. F. Ashby, "Intergranular Fracture at Elevated Temperature," Acta Metall., 23 [6] 653-66 (1975).

94A. G. Evans, J. R. Rice, and J. P. Hirth, "Suppression of Cavity Formation in Ceramics: Prospects for Superolasticity," J. Am. Ceram. Soc, 63 [7-8] $368-75$ (1980)

${ }^{95 N}$. Ridley and J. Pilling, "Cavitation in Superplastic Alloys-Experimental" '; Ch. 8, pp. 8.1-8.17 in Superplasticity. Edited by B. Baudelet and M. Suery. Centre National de la Recherche Scientifique, Paris, France, 1985.

96M. Suery, "Cavitation in Superplastic AlloysTheoretical "; Ch. 9, pp. 9.1-9.19 in Superplasticity. Edited by B. Baudelet and M. Suery. Centre Nation al de la Recherche Scientifique, Paris, France, 1985.

${ }^{97} \mathrm{~J}-\mathrm{G}$. Wang and R. Raj, "Influence of Hydrostatic Pressure and Humidity on Superplastic Ductility of Two $\beta$-Spodumene Glass-Ceramics," J. Am. Ceram. Soc., 67 [6] 385-90 (1984).

$98 \mathrm{~B}$. Kibbel and A. H. Heuer, "Exaggerated Grain Growth in $\mathrm{ZrO}_{2}$-Toughened $\mathrm{Al}_{2} \mathrm{O}_{3}$, J Am. Ceram Soc., 69 [3] 231-36 (1986).

99F. F. Lange and M. Hirlinger, "Hindrance of Grain Growth in $\mathrm{Al}_{2} \mathrm{O}_{3}$ by $\mathrm{ZrO}_{2}$ Inclusions," J. Am Ceram. Soc., 67 [3] 164-68 (1984).

${ }^{100} \mathrm{~A}$. H. Chokshi and J. R. Porter, "HighTemperature Mechanical Properties of Single-Phase Ceramic," J. Mater. Sci., 21, 705-10 (1986)

101T. G. Nieh, C. M McNally, and J. Wadsworth, "Superplasticity in Intermetallics, Alloys, and Ceramics," J. Met, 41 [9] 31-35 (1989).

102 J-G. Wang and R. Raj, "Mechanism of Superplastic Flow in Fine-Grained Ceramics Containing Some Liquid Phase," J. Am. Ceram. Soc., 67 [6] $399-409$ (1984) 


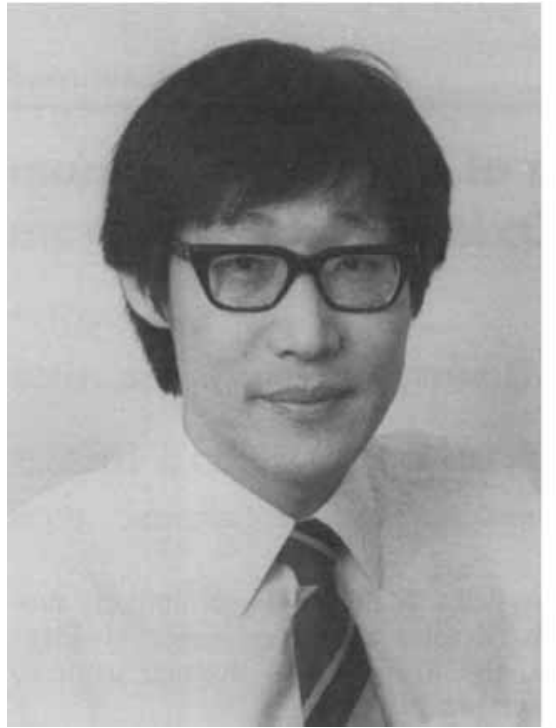

-Wei Chen is Professor of Materials Science and Engineering at the University of Michigan at Ann Arbor. A native of Taiwan, he graduated from Tsinghua University (B.S.) and University of Pennsylvania (M.S.) majoring in physics. He received his Ph.D. in metallurgy from Massachusetts Institute of Technology in 1980. Prior to joining the University of Michigan in 1986, he was a joint Assistant Professor in the Department of Nuclear Engineering and the Department of Materials Science and Engineering at MIT. He has served the American Ceramic Society as Program Chair of the Basic Science Division (1989-1990) and as an Associate Editor of the Journal (since 1990). His major publications in ceramics are on zirconia phase transformation, microstructural modeling, and mechanical properties.

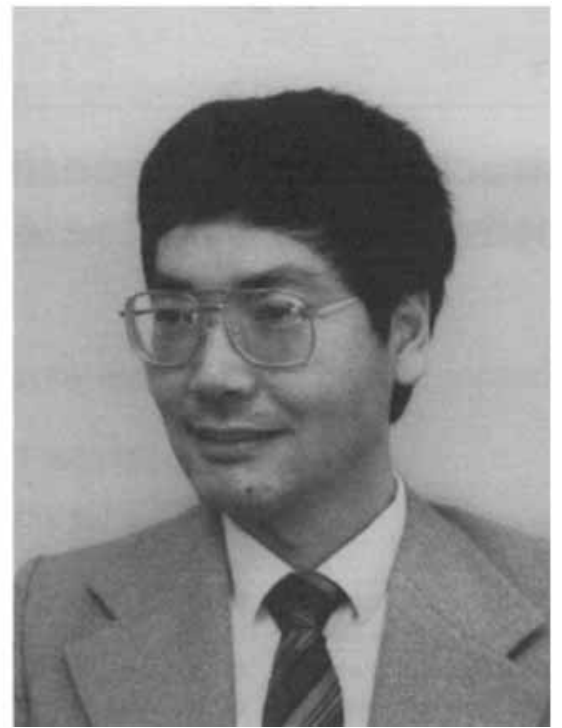

Liang An Xue is a Senior Research Fellow in the Department of Materials Science and Engineering at the University of Michigan. He received a B.S. in building materials in 1982 from Tongji University, Shanghai, China. He earned his Ph.D. in ceramics in 1987 from Leeds University, England, where he studied additives and grain-growth control of barium titanate ceramics under the supervision of Richard Brook. Prior to joining the University of Michigan in 1989, he was a Postdoctoral Associate in the Materials Science Department at Cornell University, working with Rishi Raj on the development of novel infrared window materials such as zinc sulfide/diamond composites. His main research interests include ceramic processing, superplasticity, and microstructural/property relationships in ceramics and ceramic composites. Dr. $X$ ue is the author or coauthor of 20 scientific papers and 1 patent. He is a member of the Institute of Ceramics, U.K., and a member of the American Ceramic Society. 